Flores, P., A parametric study on the dynamic response of planar multibody systems with multiple clearance joints. Nonlinear Dynamics, Vol. 61(4), pp. 633-653, 2010 (DOI: 10.1007/s11071-010-9676-8)

\title{
A parametric study on the dynamic response of planar multibody systems with multiple clearance joints
}

\author{
Paulo Flores $^{1 *}$ \\ ${ }^{1}$ Departamento de Engenharia Mecânica, Universidade do Minho, \\ Campus de Azurém, 4800-058 Guimarães, Portugal
}

\begin{abstract}
A general methodology for dynamic modeling and analysis of multibody systems with multiple clearance joints is presented and discussed in this paper. The joint components that constitute a real joint are modeled as colliding bodies, being their behavior influenced by geometric and physical properties of the contacting surfaces. A continuous contact force model, based on the elastic Hertz theory together with a dissipative term, is used to evaluate the intra-joint contact forces. Furthermore, the incorporation of the friction phenomenon, based on the classical Coulomb's friction law, is also discussed. The suitable contact-impact force models are embedded into the dynamics of multibody systems methodologies. An elementary mechanical system is used to demonstrate the accuracy and efficiency of the presented approach, and to discuss the main assumptions and procedures adopted. Different test scenarios are considered with the purpose of performing a parametric study for quantifying the influence of the clearance size, input crank speed and number of clearance joints on the dynamic response of multibody systems with multiple clearance joints. Additionally, the total computation time consumed in each simulation is evaluated in order to test the computational accuracy and efficiency of the presented approach. From the main results obtained in this study, it can be drawn that clearance size and the operating conditions play a crucial role in predicting accurately the dynamic responses of multibody systems.
\end{abstract}

Keywords: Multibody dynamics, Clearance joints, Contact forces, Friction effect

\footnotetext{
* Corresponding author: Phone: + 352 253510220; Fax: + 351253 516007; E-mail: pflores@dem.uminho.pt
} 


\section{Introduction}

Over the last few decades, the Computer-Aided of Mechanical Systems emerged as an important scientific part of the Applied Mechanics field, with important applications in several branches of engineering [1-5]. This has been made possible thanks to the impressive improvements of the computers at the level of both hardware and software, due to the creation of robust and accurate computational tools, and due to the demand for analysis of complex multibody mechanical systems. Decades ago, the design of machines and components was based on trial and error and knowledgeable craftsmanship. Later, algebraic methods for analysis eliminated part of the limitations of the trial and error and lead to documented methods used in the design of mechanical components $[5,6]$. In today's industry there is little room for error and a great need for optimized and cost effective production of components and machines with high reliability and durability. Still, all areas of research are to some point based on the construction of models and, therefore, on assumptions and approximations. The development of faster data processing capabilities allowed more accurate and detailed methodologies and techniques inspired to improve the already existing formulations. The analysis of complex multibody systems is an area where in the past few decades faster data processing has lead to an increased research effort. This includes kinematic and dynamic analysis, synthesis and optimization of the motion forces in multibody systems [3-6].

All of the mechanical systems do not have perfect kinematic joints due to functional tolerances between the adjacent segments [7]. Either due to the loads carried by the mechanical devices or misalignments that are required for their operation, real joints must be lubricated [8] or include bushings [9], generally made with metals and polymers. By using rubber bushings a conventional mechanical joint is transformed into a joint with clearance allowing for the mobility of the over constrained system in which it is used [10]. Therefore, appropriate tribological models must be devised in the framework of their application in general multibody systems [11]. The characterization of the normal contact forces in the non lubricated joints is realized by using the continuous contact force model [12] while their tangential forces are obtained by using appropriate friction force models [13]. Joints with rubber bushings are usually described by the methodology suggested by Park and Nikravesh [10]. However, this is a linear model that does not include coupling between radial and axial or bending loading. A more advanced model for rubber bushings is realized by obtaining the static nonlinear response of the rubber bushings using finite elements and implementing the force-displacement curves as carpet plots in the computational code that supports the analysis [14].

The serious consequences of the clearance joints on the behavior of the multibody systems have motivated various theoretical and experimental investigations over the last three 
decades [15-23]. Furthermore, mechanical systems with clearance joints can have a predictable nonlinear dynamic response [24-26]. This is an important feature for the design and control of these systems. Consequently, proper modeling of clearance joints in mechanical systems is required to achieve better understanding of the dynamic performance of the machines and mechanisms. This aspect gains paramount importance due to the demand for the proper design of the real joints in many industrial applications. The general purpose computational tools used for the design and analysis of multibody systems have a wide number of mechanical systems modeling features that require the description of rigid or flexible bodies for which geometry, mass, center of mass, moment of inertia, and other relevant properties are defined [27, 28]. The computational codes also provide a large library of kinematic joints that constrain relative degrees of freedom between connected bodies. The kinematic joints available in the commercial programs are represented as ideal joints, that is, there are no clearances or deformations in them. Thus, modeling the dynamics of multibody systems with clearances and imperfections is a challenging issue in mechanical design and much work still remains to be done to achieve satisfactory modeling tools.

The primary objective of this work is to explore the mathematical modeling of real joints in the multibody systems. Furthermore, a parametric study of a planar mechanical system is performed in order to quantify the influence of the main parameters on the dynamic response of mechanical systems with multiple clearances joints. The selected parameters are the clearance size, the input crank speed, the number of joints modeled as clearance joints. During the numerical simulations the time of computation is evaluated in order to analyze the computational efficiency of the presented methodology. In general, the present research work is expected to be of great use in the analysis of multibody systems with clearance joints, namely in regard to the design and control tasks of such systems.

In a broad sense, there are two main approaches to model multibody systems with contact-impact events, namely the regularized models [29] and non-smooth dynamics formulation [30]. The regularized approach is in fact a penalty method in which the contact forces and deformations are modeled by a set of spring-damper elements that represent the surface compliance of the contacting bodies [12]. This approach is quite simple, very straightforward to implement and presents also a good computational efficiency. In addition, in the regularized approach, there are no impulses at the instant of contact, therefore, there is no need for impulsive dynamics calculations and the contact loss can be easily determined from position and velocity data [31]. One of the disadvantages associated with this formulation is that it can introduce highly-frequency dynamics into the system, due to the presence of stiff springs in compliant surfaces. If these dynamics require the integration algorithm to take smaller steps, then the speed of simulation will be strongly penalized [32]. Another drawback of the 
regularized approach is that the difficulty to chosen the contact parameters such as the equivalent stiffness or the degree of nonlinearity of the deformation, especially for complex contact scenarios [33]. An alternative way to treat the contact-impact problems in multibody systems is to use the non-smooth dynamics approach, namely the Linear Complementary Problem (LCP) $[34,35]$ and Differential Variational Inequality (DVI) [36, 37]. The complementarity formulations associated with the Moreau's time-stepping algorithm for contact modeling in multibody systems have used by many researchers [38-40]. Assuming that the contacting bodies are truly rigid, as opposed to locally deformable or penetrable bodies as in the penalty approaches, the complementarity formulations resolve the contact dynamics problem by using the unilateral constraints to compute contact impulses or forces to prevent penetration from occurring. Thus, at the core of the complementarity approach is an explicit formulation of the unilateral constraints between the contacting rigid bodies [41]. The basic idea of complementarity in unilateral multibody systems can be stated as for a unilateral contact either relative kinematics is zero and the corresponding constraint forces are zero, or vice versa. The product of these two groups of quantities is always zero. This leads to a complementarity problem and constitutes a rule which allows the treatment of multibody systems with unilateral constraints [42-45]. One of the first published works on the complementarity problems is due to Signorini [46], who introduced an impenetrability condition in the form of a Linear Complementary Problem. Later, Moreau [47] and Panagiotopoulos [48] also applied the concept of complementarity to study nonsmooth dynamic systems. Pfeiffer and Glocker [34] extended the developments of Moreau and Panagiotopoulos to multibody dynamics with unilateral contacts, being the complementarity considered of paramount importance. Indeed, complementarity problems proved to be a very useful way to formulating problems involving discontinuities [49-52]. In turn, the DVI has been recognized to be a powerful tool to deal with multiple contact problems in multibody dynamics. This approach has the advantage that it does not need the use of small time steps as in the case of penalty approaches, which means that simpler integrator schemes can be used such as the Euler method [36]. However, the algorithmic procedures that results from DVI approach is of great complexity. This formalism has been used with success by Tasora et al. [37] to model and analyze multibody systems involving hundreds of thousand contacts. The DVI approaches are also interesting in the measure that they can easily deal with friction problems without need to modify Coulomb's friction law. In short, the different methods to deal with contact-impact events in multibody systems have inherently advantages and disadvantages for each particular application. To the belief of author, none of the formulations briefly described above can a-priori be said to be superior compared to other for all applications. It is a fact that a specific multibody problem might be easier to describe by one formulation, but this does not yield a general predominance of this formulation in all situations. 


\section{Modeling revolute clearance joints}

In standard multibody models it is assumed that the connecting points of two bodies, linked by an ideal revolute joint, are coincident. The introduction of the clearance separates these two points. Figure 1 shows a typical connection with clearance joints found in planar multibody systems, where the clearance size is strongly exaggerated in order to illustrate the phenomena associated with the revolute joints with clearance, namely, the bouncing effect. In a revolute clearance joint, when contact exists between the journal and bearing, a contact-impact force is applied perpendicular to the plane of collision. The force is typically applied as a spring damper element. If this element is linear, the approach is known as the Kelvin Voigt model [53]. If the relation is nonlinear the model is generally based on the Hertz contact law [54].

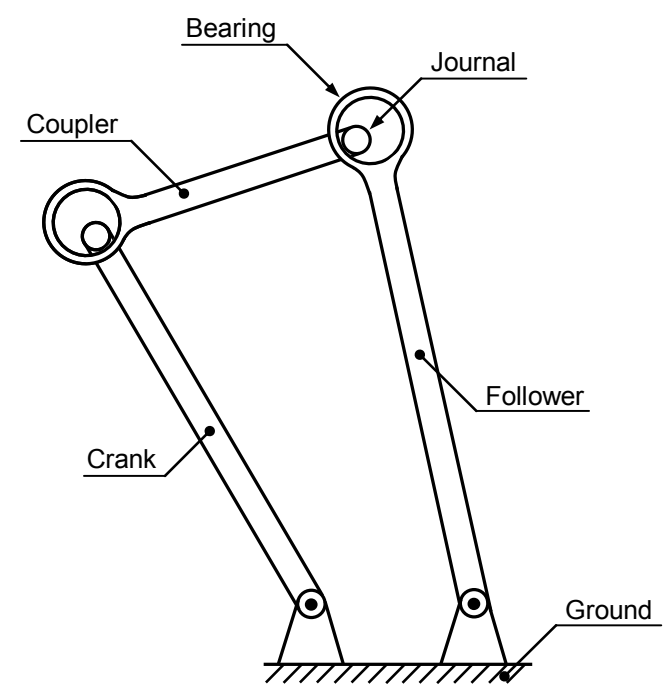

Figure 1. Typical connection with clearance joints found in planar multibody systems.

Figure 2 depicts a revolute joint with clearance, that is, the so-called journal bearing, where the difference in diameters between the bearing and the journal defines the diametric clearance. Several published research works focused on the different modes of motion of the journal inside the bearing boundaries. Most of these consider a three mode model for predicting the dynamical response of articulated systems with revolute clearance joints [55-61]. The three different modes of journal motion inside the bearing are the contact or following mode, the free flight mode, and the impact mode, which are illustrated in Fig. 2. 


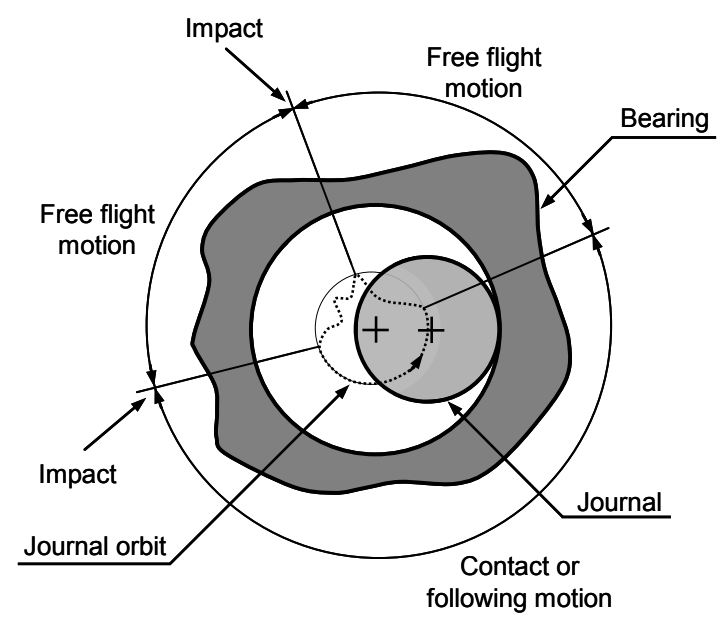

Figure 2. Types of journal motion inside the bearing boundaries.

In the contact or following mode, the journal and the bearing are in permanent contact and a sliding motion related to each other is assumed to exist. In this mode the relative penetration depth varies along the circumference of the bearing. In practice, this mode is ended when the journal and bearing separate from each other and the journal enters in free flight mode. In the free flight mode, the journal can move freely inside the bearing boundaries, that is, the journal and the bearing are not in contact, hence, and no reaction force develop at the joint. In the impact mode, which occurs at the termination of the free flight mode, impact forces are applied and removed in the system. This mode is characterized by a discontinuity in the kinematic and dynamic characteristics, and a significant exchange of momentum occurs between the two impacting bodies. At the termination of the impact mode, the journal can enter either a free flight or a following mode.

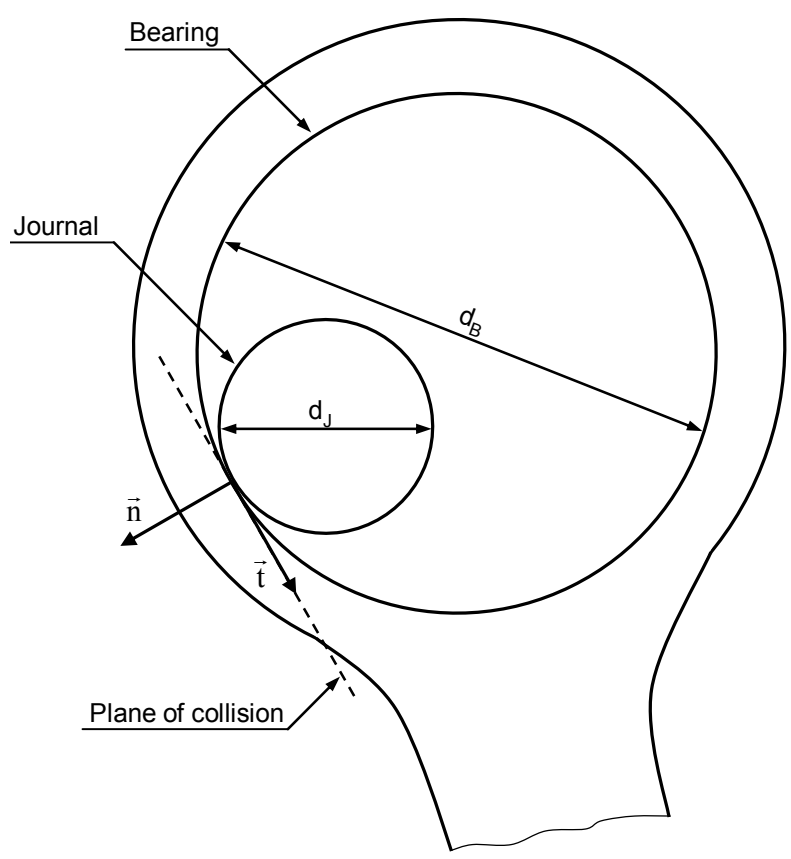

Figure 3. Generic configuration of a revolute joint with clearance in a multibody system. 
Figure 3 shows a generic configuration of a revolute joint with clearance in a multibody system. In the dynamic simulation, the behavior of the revolute clearance joint is treated as an oblique eccentric impact between the journal and the bearing. The mechanics of this type of impact involves both the relative normal velocity and the relative tangential velocity [62]. When the impact occurs, an appropriate contact law must be applied and being the resulting forces introduced as generalized forces in the system's equations of motion [1].

Regarding to Fig. 3, the relative penetration vector between journal and bearing walls can be defined as

$$
\boldsymbol{\delta}=\mathbf{e}-\left(\frac{d_{B}-d_{J}}{2}\right) \mathbf{n}
$$

where $\mathbf{e}$ is the eccentricity vector, that is, the vector that defines the distance between journal and bearing centers, $d_{B}$ and $d_{J}$ are the bearing and journal diameters and $\mathbf{n}$ is the vector that defines the normal direction of the plane of collision.

The magnitude of the penetration depth can be evaluated as

$$
\delta=e-c
$$

in which $c$ represents the radial clearance defined as

$$
c=\frac{d_{B}-d_{J}}{2}
$$

Since the most suitable and sophisticated contact-impact force models are dependent on the contact velocities, it is important to evaluate these velocities in order to account for the dissipative effects during the contact-impact process [11]. In particular, in the continuous force contact model it is necessary to calculate the relative velocity between impacting surfaces. The relative velocity vector between bearing and journal can be expressed by

$$
\mathbf{v}=\frac{d\left(\left\|\mathbf{r}_{B}^{C}-\mathbf{r}_{J}^{C}\right\|\right)}{d t} \mathbf{n}+\left(\left\|\mathbf{r}_{B}^{C}-\mathbf{r}_{J}^{C}\right\|\right)\left(\omega_{B}-\omega_{J}\right) \mathbf{t}
$$

where $\mathbf{r}_{B}^{C}$ and $\mathbf{r}_{J}^{C}$ are the position vectors of the contact points in the bearing and journal, $\mathbf{n}$ and $\mathbf{t}$ are the normal and tangential vectors, and $\omega_{B}$ and $\omega_{J}$ are the bearing and journal angular velocities. It should be highlighted that vector $\mathbf{t}$ is obtained by rotating the vector $\mathbf{n}$ in the counter clockwise direction by $90^{\circ}$.

The relative velocity between the contact points is projected onto the plane of collision and onto the normal plane of collision, yielding a relative tangential velocity, $v_{T}$, and a relative normal velocity, $v_{N}$. The normal relative velocity determines whether the contact bodies are approaching or separating. Similarly, the tangential relative velocity determines whether the contact bodies are sliding or sticking. The relative scalar velocities, normal and tangential to the 
plane of collision are found by projecting the relative impact velocity onto each one of these directions

$$
\begin{aligned}
& v_{N}=\mathbf{v}^{\mathrm{T}} \mathbf{n} \\
& v_{T}=\mathbf{v}^{\mathrm{T}} \mathbf{t}
\end{aligned}
$$

Although a revolute joint with clearance does not constrain any degree of freedom from the mechanical system, as the ideal joint does, it imposes some restrictions, limiting the journal to move within the bearing. Thus, when the clearance is present in a revolute joint, two kinematic constraints associated with an ideal joint are removed and two degrees of freedom are introduced instead. The dynamics of the joint is then controlled by contact-impact forces between the journal and bearing. Thus, whilst a perfect revolute joint in a mechanical system imposes kinematic constraints, a revolute clearance joint leads to force constraints. Therefore, joints with clearance can be defined as force-joints instead of kinematic joints.

When contact between the journal and bearing takes place, contact-impact forces act at the contact points. The contributions of these contact-impact forces to the external forces applied to the mechanical system are found by projecting them onto the $X$ and $Y$ directions. Since these forces do not act through the centre of mass of the bearing and journal bodies the moment components for each body need to be evaluated. The suitable numerical models for normal and tangential contact-impact forces are presented and discussed in the following section.

In short, in dynamic analysis, the deformation is known at every time step from the configuration of the system and the forces are evaluated based on the state variables. With the variation of the contact force during the contact period, the dynamic system's response is obtained by simply including updated forces into the equations of motion. Since the equations of motion are integrated over the period of contact, this approach results in a rather accurate response. Furthermore, this methodology accounts for the changes in the system's configuration during the contact periods. The methodology presented in the previous sections is quite simple and generic to apply in the dynamic modeling and analysis of any mechanical system. For details on this issue, the interested reader is referred to the work developed by Flores [58].

\section{Numerical models for contact forces}

Impact, such as it happens in a revolute clearance joint, is one of the most common types of dynamic loading conditions that give rise to impulsive forces, which in turn excite higher vibration modes and affect the dynamic characteristics of the mechanical systems. Thus, for a revolute joint with clearance, the contact between the journal and bearing can be modeled by the well known Hertz contact law [54] 


$$
F_{N}=K \delta^{n}
$$

where $K$ is the stiffness coefficient and $\delta$ is the relative penetration. The exponent $n$ is set to 1.5 . The parameter $K$ depends on the material and geometric properties of the contacting surfaces. For instance, for two spheres in contact the generalized stiffness coefficient is a function of the radii of the spheres $i$ and $j$ and the material properties as [63]

$$
K=\frac{4}{3\left(\sigma_{i}+\sigma_{j}\right)}\left[\frac{R_{i} R_{j}}{R_{i}+R_{j}}\right]^{\frac{1}{2}}
$$

where the material parameters $\sigma_{i}$ and $\sigma_{j}$ are given by,

$$
\sigma_{k}=\frac{1-v_{k}^{2}}{E_{k}}, \quad(k=i, j)
$$

the quantities $v_{k}$ and $E_{k}$ are the Poisson's ratio and the Young's modulus associated with each sphere, respectively.

Hertz contact law given by Eq. (7) is a pure elastic model, that is, it does not include any energy dissipation. Lankarani and Nikravesh [12] extended the Hertz contact law to include energy loss due to internal damping as follows

$$
F_{N}=K \delta^{n}\left[1+\frac{3\left(1-c_{e}^{2}\right)}{4} \frac{\delta^{2}}{\delta^{(-)}}\right]
$$

where the stiffness coefficient $K$ can be evaluated by Eqs. (8) and (9), $c_{e}$ is the restitution coefficient, $\&^{\&}$ is the relative penetration velocity and $\&^{(-)}$is the initial impact velocity.

The Coulomb's friction law of sliding friction can represent the most fundamental and simplest model of friction between dry contacting surfaces. When sliding takes place, the Coulomb law states that the tangential friction force $F_{T}$ is proportional to the magnitude of the normal contact force, $F_{N}$, at the contact point by introducing a coefficient of friction $c_{f}$ [64]. The Coulomb's friction law is independent of relative tangential velocity. In practice this is not true, because friction forces can depend on many parameters such as material properties, temperature, surfaces cleanliness, and velocity of sliding. Therefore, a continuous friction force-velocity relationship is desirable. Furthermore, the application of the original Coulomb's friction law in a general-purpose computational program may lead numerical difficulties because it is a highly nonlinear phenomenon that may involve switching between sliding and stiction conditions. In order to avoid such difficulties, a modified Coulomb law is used [58]

$$
F_{T}=-c_{f} c_{d} F_{N} \frac{\mathbf{v}_{T}}{\left\|\mathbf{v}_{T}\right\|}
$$

where $c_{f}$ is the friction coefficient, $F_{N}$ is the normal force, $\mathbf{v}_{T}$ is the relative tangential velocity and $c_{d}$ is a dynamic correction coefficient, which is expressed as 


$$
c_{d}=\left\{\begin{array}{ccc}
0 & \text { if } & v_{T} \leq v_{0} \\
\frac{v_{T}-v_{0}}{v_{1}-v_{0}} & \text { if } & v_{0} \leq v_{T} \leq v_{1} \\
1 & \text { if } & v_{T} \geq v_{1}
\end{array}\right.
$$

where $v_{0}$ and $v_{l}$ are given tolerances for the tangential velocity [58]. The dynamic correction factor $c_{d}$ prevents that the friction force changes direction in the presence of almost null values of the tangential velocity, which would be perceived by the integration algorithm as a dynamic response with high frequency contents, forcing it to reduce the time step size.

\section{Multibody systems formulation}

The equations of motion for a dynamic multibody system subjected to holonomic constraints can be stated in the form [1]

$$
\left[\begin{array}{cc}
\mathbf{M} & \boldsymbol{\Phi}_{\mathrm{q}}^{\mathrm{T}} \\
\boldsymbol{\Phi}_{\mathrm{q}} & \mathbf{0}
\end{array}\right]\left\{\begin{array}{l}
\boldsymbol{q} \\
\lambda
\end{array}\right\}=\left\{\begin{array}{l}
\mathbf{g} \\
\gamma
\end{array}\right\}
$$

with the reference frame placed at the center of mass for each body, $\mathbf{M}$ is the system mass matrix, $\boldsymbol{\Phi}_{\mathbf{q}}$ is the Jacobian matrix of constraint equations, the vector $\boldsymbol{\&}$ contains the generalized state accelerations, $\lambda$ is the vector that contains the Lagrange multipliers, $\mathbf{g}$ is the vector of generalized forces and $\boldsymbol{\gamma}$ is the vector of quadratic velocity terms that is used to describe Coriolis and centrifugal terms in the equations of motion [1]. Equation (13) is formed as a combination of the equations of motion and kinemtaic constraint equations, often referred to as a mixed set of differential and algebraic equations.

A set of initial conditions (positions and velocities) is required to start the dynamic simulation. The selection of the appropriate initial conditions plays a key role in the prediction of the dynamic performance of mechanical system [65]. In the present work, the initial conditions are based on the results of kinematic simulation of mechanical system in which all the joints are assumed to be ideal, that is, without clearance. The subsequent initial conditions for each time step in the simulation are obtained in the usual manner from the final conditions of the previous time step [1]. In order to stabilize or keep under control the constraints violation, Eq. (13) is solved using the Baumgarte stabilization technique [66]. In turn, the integration process is performed using a predictor-corrector algorithm with both variable step size and order [67].

The use of numerical algorithms with automated adjust step size is particularly important in contact problems whose dynamic response is quite complex due to the suddenly change in kinematic configuration. In such events, the use of a constant time step is computationally inefficient and the system could be overlooked due to insufficient time resolution. Thus, automated time step size adaptability is therefore a crucial part of the dynamic solution 
procedure. Moreover, the abrupt configuration changes caused by rapidly variation of contact forces are source of stiffness, since the natural frequency of the system is widely spread. Thus, the time step size must be adjusted in order to capture the fast and low components of the system response [1].

\section{Results and discussion}

This section contains extensive results obtained from computational simulations of a planar slider-crank mechanism with multiple clearance joints when subjected to different test scenarios in order to carry out a parametric study. This study takes into account the main functional parameters of the slider-crank mechanism, chiefly, clearance size, input crank speed and number of joints considered as clearance joints. The computational time consumed during numerical simulations is used as a measured of the computational efficiency of the proposed methodologies.

\subsection{Description of the slider-crank mechanism}

Figure 4 shows the configuration of the slider-crank mechanism selected, which consists of four rigid bodies that represent the crank, connecting rod, slider and ground, one ideal revolute joint and one ideal translational joint. Two revolute joints with clearance exist between the crank and connecting rod, and between the connecting rod and slider. The length and inertia characteristics of this mechanism are listed in Table 1. Due to the presence of the two non-ideal joints this system has five degrees of freedom. The acceleration due to gravity is taken as acting in the negative $Y$ direction and the mechanism is defined as moving in a vertical plane.

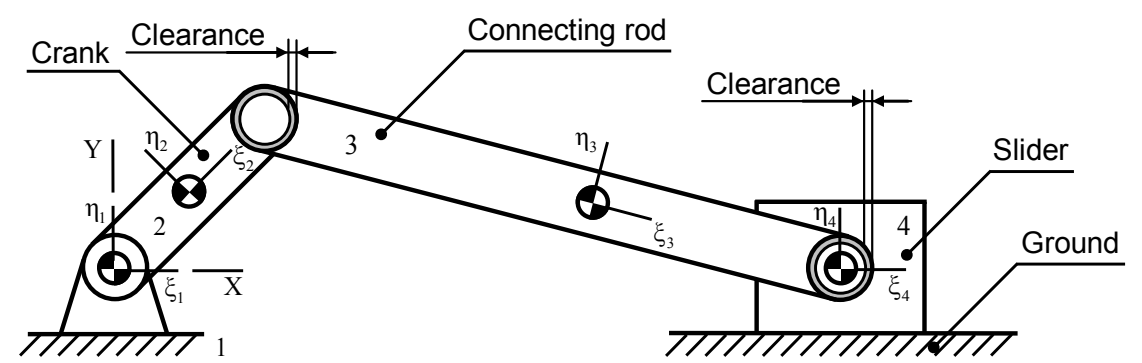

Figure 4. Slider-crank mechanism with two revolute joints with clearance.

\begin{tabular}{cccc}
\hline Body Nr. & Length $[\mathrm{m}]$ & Mass $[\mathrm{kg}]$ & Moment of inertia $\left[\mathrm{kgm}^{2}\right]$ \\
\hline 2 & 0.05 & 0.30 & 0.00010 \\
3 & 0.12 & 0.21 & 0.00025 \\
4 & - & 0.14 & 0.00010 \\
\hline
\end{tabular}

Tab. 1: Geometric and inertia properties of the slider-crank mechanism. 
The crank, which is the driving link, rotates with a constant angular velocity of $5000 \mathrm{rpm}$. The initial configuration of the mechanism is defined with the crank and the connecting rod collinear, and the journal and bearing centers coincident. Furthermore, the initial positions and velocities necessary to start the dynamic analysis are obtained from kinematic simulation of the slider-crank mechanism in which all the joints are considered to be ideal. Table 2 gives the main parameters used for the different models, required to characterize the problem and for the numerical methods, required to solve the system dynamics.

\begin{tabular}{cccc}
\hline Nominal bearing diameter & $20.0 \mathrm{~mm}$ & Poisson's ratio & 0.3 \\
Standard diametric clearance & $0.05 \mathrm{~mm}$ & Integrator algorithm & Gear \\
Coefficient of restitution & 0.9 & Baumgarte $-\alpha, \beta$ & 5 \\
Coefficient of friction & 0.01 & Integration step size & $1 \times 10^{-6} \mathrm{~s}$ \\
Young's modulus & $207 \mathrm{GPa}$ & Total time of simulation & $10.0 \mathrm{~s}$ \\
\hline
\end{tabular}

Tab. 2: Parameters used in the dynamic simulations of the slider-crank mechanism with clearance joints.

The diametric clearance size of the non-ideal revolute joints is taken to be equal to $0.05 \mathrm{~mm}$, which corresponds to the actual clearance size in a typical journal-bearing with nominal dimensions used in the present work. For example, for a journal-bearing in which the nominal diameter falls into the interval between 18 and $30 \mathrm{~mm}$, the minimum and maximum recommended diametric clearance sizes are 0.02 and 0.06 , respectively [68].

In what follows, several numerical results are presented and analyzed to demonstrate the computational implementation and efficiency of the proposed methodologies. The dynamic response of the slider-crank mechanism is quantified by plotting the slider velocity and acceleration, joint reaction force and the reaction moment that acts on the crank. In addition, the journal center orbit inside the bearing boundaries and the maps that relates the eccentricity and eccentricity velocity are plotted too. The global results are relative to two complete crank rotations after steady state has been reached. Furthermore, the results for this system are compared with the dynamic behavior of the slider mechanism with ideal joints only.

\subsection{Influence of the clearance size: one clearance joint}

In this section, the influence of the clearance size on the dynamic behavior of the slidercrank mechanism is investigated. In the simulation of the mechanism, only one joint is modeled as clearance joint, namely, the joint that connects the connecting rod and slider. 
Figure 5 shows the results for the case in which the diametric clearance size is equal to $0.05 \mathrm{~mm}$ and crank speed of $5000 \mathrm{rpm}$, as it was presented in the previous section. Note that the results are plotted against those obtained for ideal joint, being reported for the two full crank rotations after steady-state has been reached. The results plotted are the slider velocity and acceleration, the reaction force that is produced in the clearance joint, the crank reaction moment that acts on the crank, the trajectories of the journal center relative to the bearing center and, finally, the Poincaré map. The eccentricity and eccentricity velocity in the clearance joint are the parameters selected to plot this map.

In Fig. 5(a) it is observed that the existence of a clearance joint does not influence the slider velocity in a significant manner. In sharp contrast, the slider acceleration is strongly affected by the contact-impact forces that takes place between journal and bearing contacting surfaces in the clearance joint. The slider acceleration is subjected to peaks caused by contact forces that are propagated through the rigid bodies of the mechanism, as perceived in Fig. 5(b) where the acceleration of the slider is displayed. The same phenomena can be observed in the curve of joint reaction force and crank moment represented by Figs. 5(c) and 5(d), respectively. As far as the trajectory of the journal center relative to the bearing center is concerned, only one type of motion between the two bodies is observed, namely the permanent or continuous contact mode. The relative penetration depth between the journal and bearing is visible by the lines of the journal path that are plotted outside the clearance circle, as illustrated in Fig. 5(e). From the Poincaré map of Fig. 5(f) it can be concluded that the behavior of the slider-crank mechanism modeled with a clearance joint tends to be aperiodic, or even chaotic, due to the nonlinear nature of the contact-impact phenomena verified between the joint components. This conclusion can easily be explained based on the spread out nature of the Poincaré map. In fact, non periodic responses are extremely sensitive to initial conditions and are densely filled by orbits or points in the Poincaré map. A complicated looking phase in a Poincaré map is one indicator of chaotic motion. Quasi-periodic orbits fill up the Poincaré maps as the chaotic orbits, but they do so in a fully predictable manner since there is no sensitive dependence on the initial conditions [69]. 


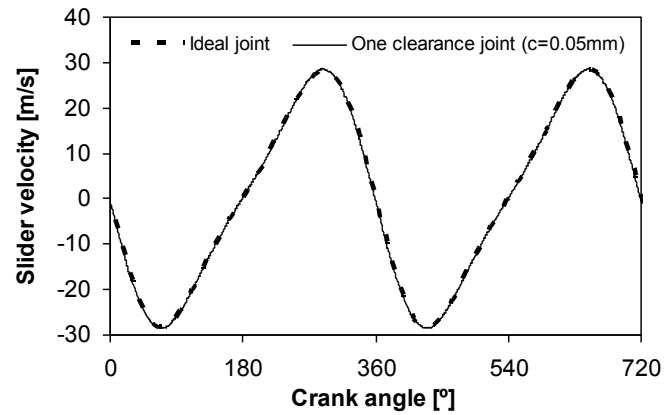

(a)

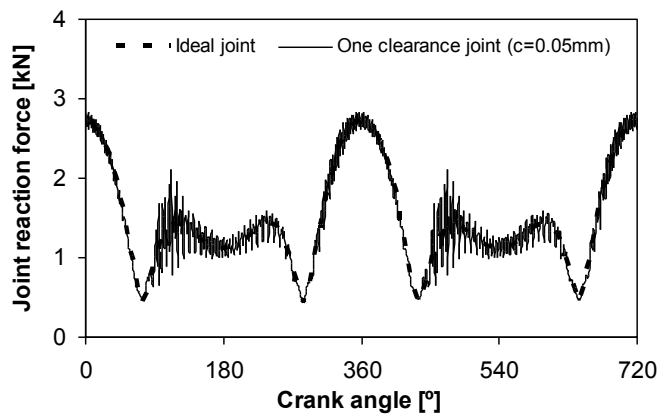

(c)

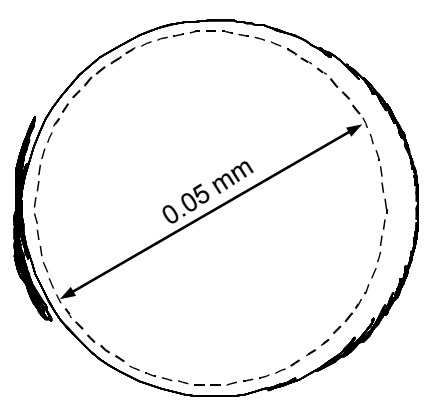

(e)

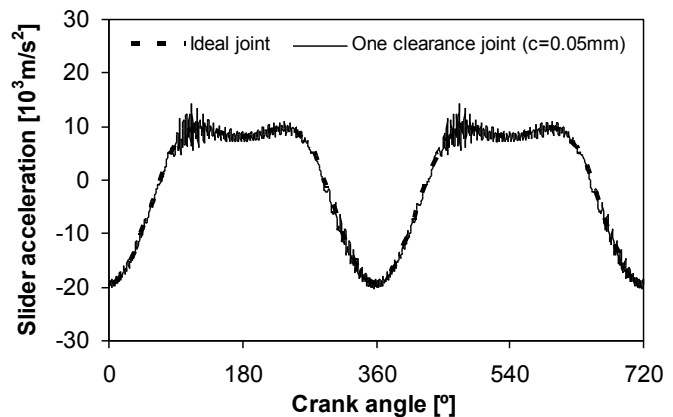

(b)

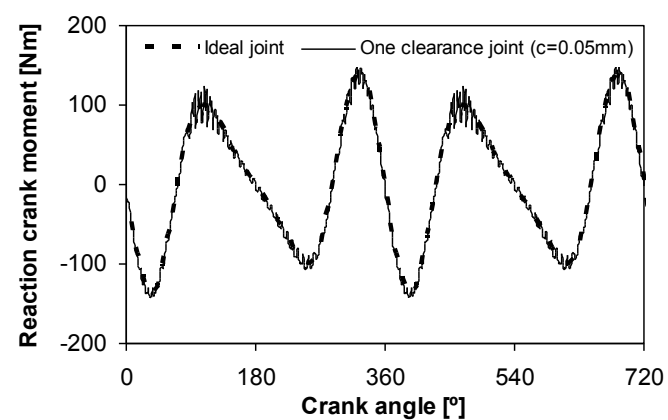

(d)

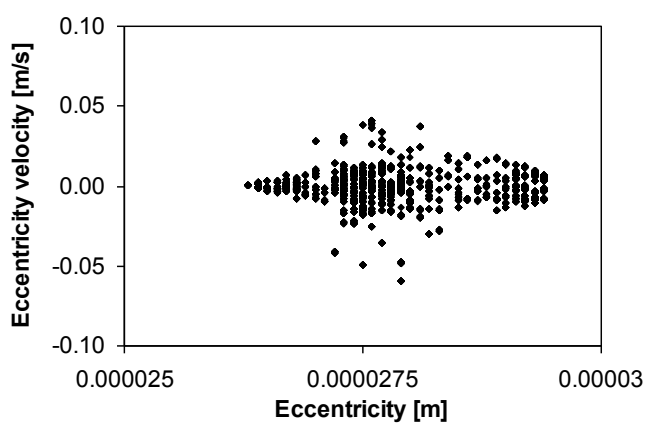

(f)

Figure 5. (a) Slider velocity; (b) Slider acceleration; (c) Joint reaction force at the clearance joint; (d) Crank moment required to maintain its angular velocity constant; (e) Journal center trajectory relative to the bearing center; (f) Poincaré map. 


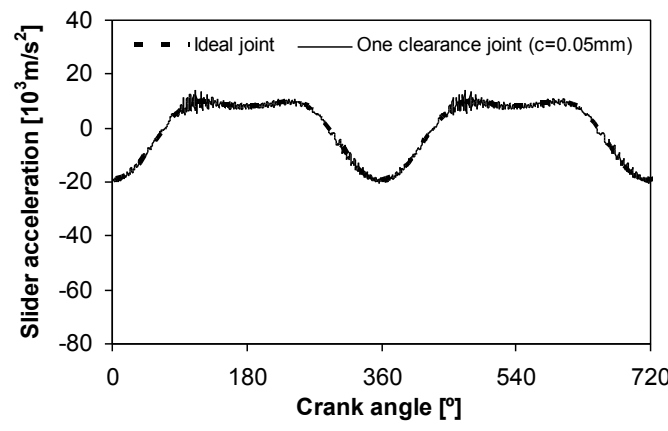

(a)

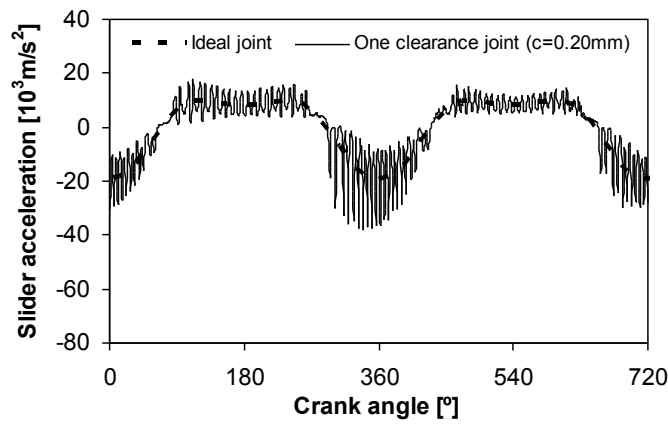

(c)

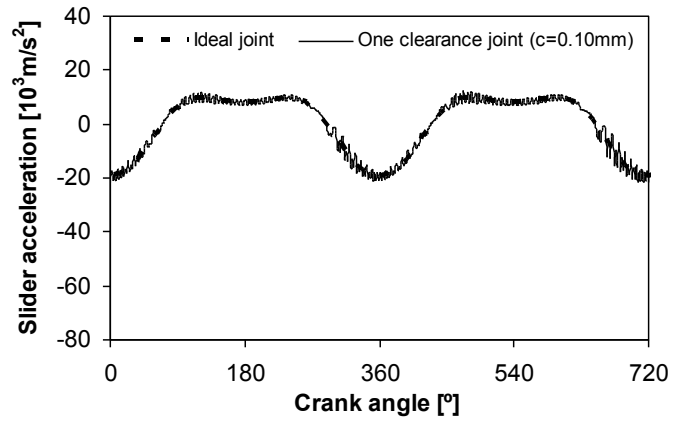

(b)

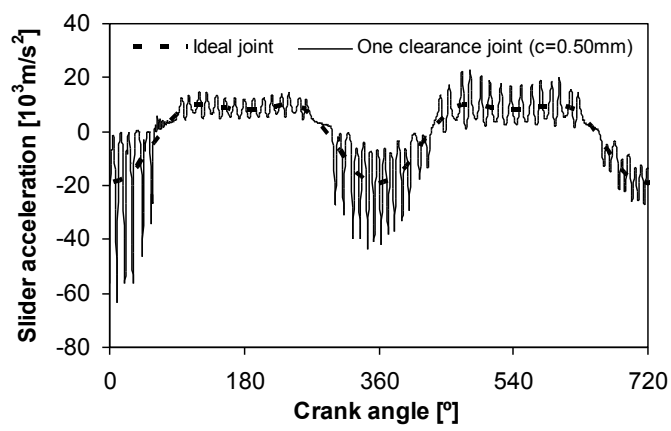

(d)

Figure 6. Slider acceleration for different diametric clearance sizes: (a) $c=0.05 \mathrm{~mm}$; (b) $\mathrm{c}=0.10$ $\mathrm{mm}$; (c) $\mathrm{c}=0.20 \mathrm{~mm}$; (d) $\mathrm{c}=0.50 \mathrm{~mm}$.

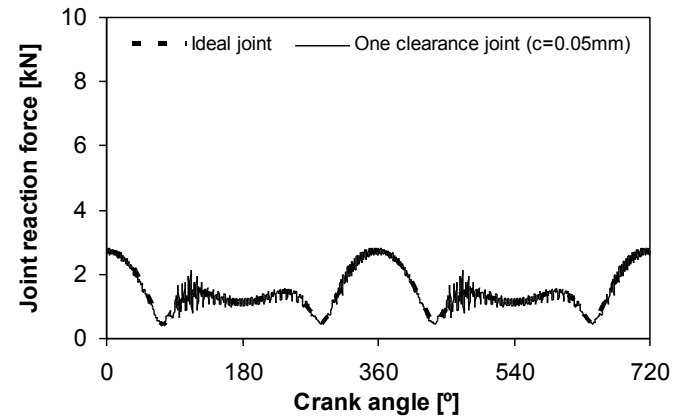

(a)

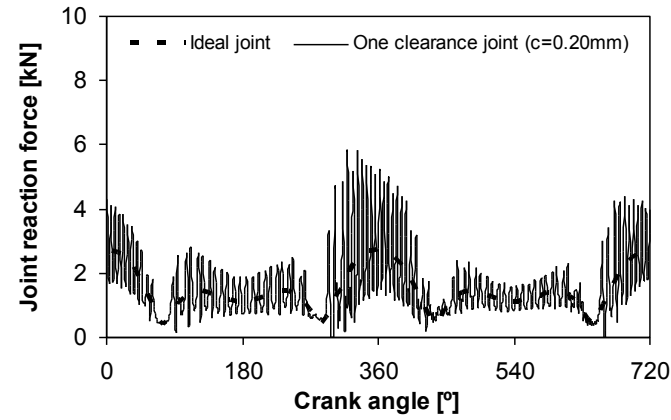

(c)

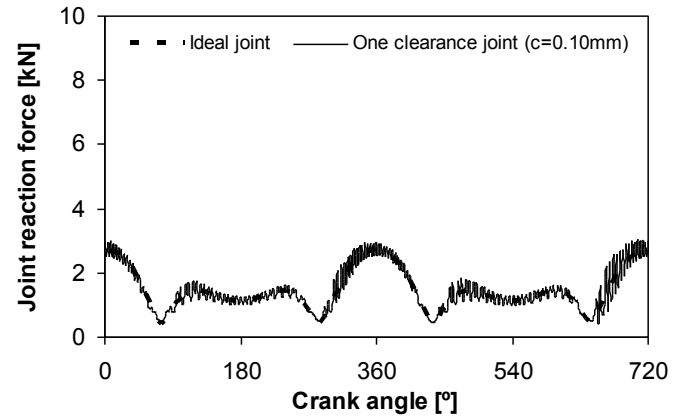

(b)

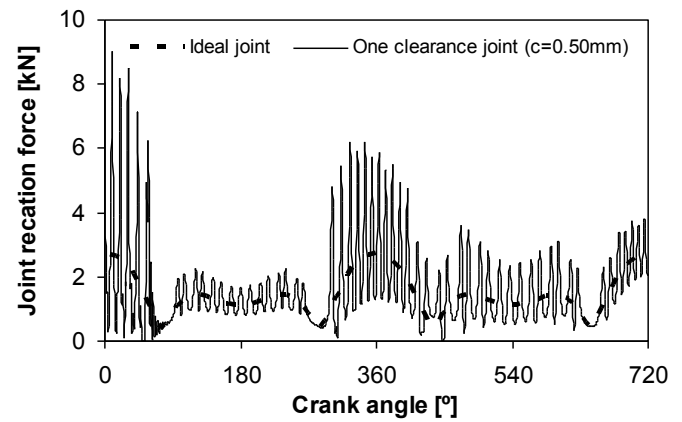

(d)

Figure 7. Joint reaction force for different diametric clearance sizes: (a) $c=0.05 \mathrm{~mm}$; (b) $c=0.10$ $\mathrm{mm}$; (c) $\mathrm{c}=0.20 \mathrm{~mm}$; (d) $\mathrm{c}=0.50 \mathrm{~mm}$. 


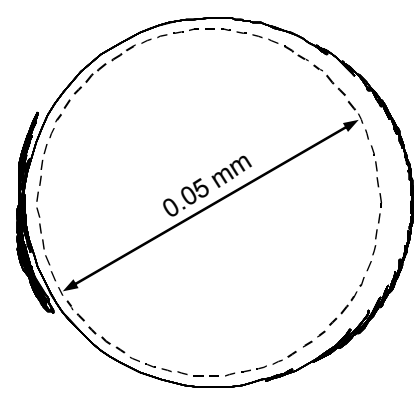

(a)

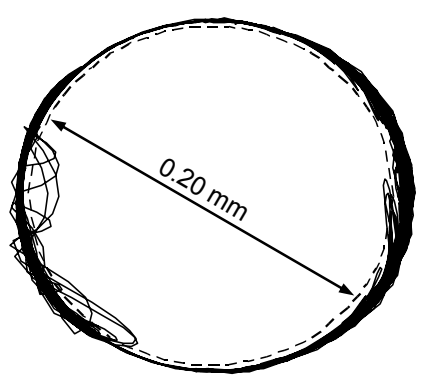

(c)

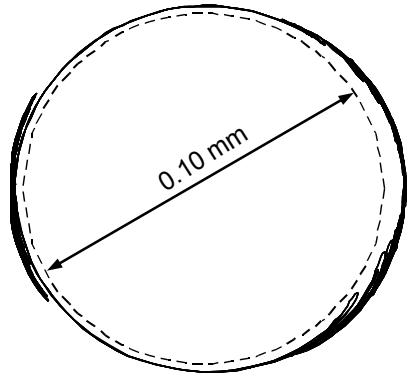

(b)

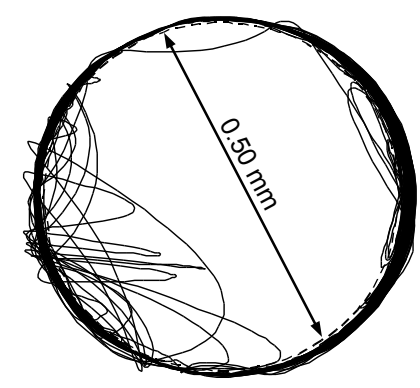

(d)

Figure 8. Journal trajectories for different diametric clearance sizes: (a) $\mathrm{c}=0.05 \mathrm{~mm}$; (b) $\mathrm{c}=0.10$ $\mathrm{mm}$; (c) $\mathrm{c}=0.20 \mathrm{~mm}$; (d) $\mathrm{c}=0.50 \mathrm{~mm}$.

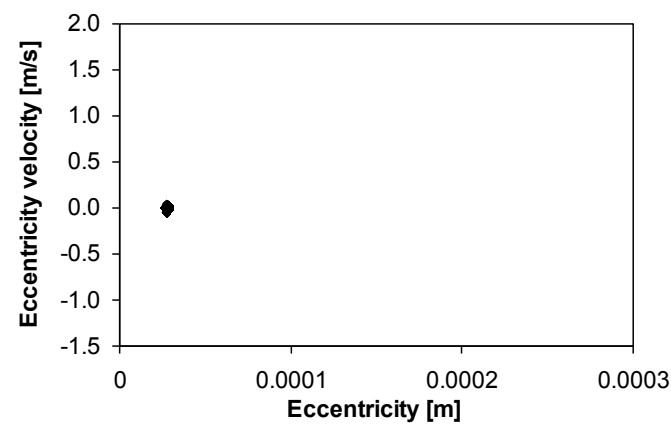

(a)

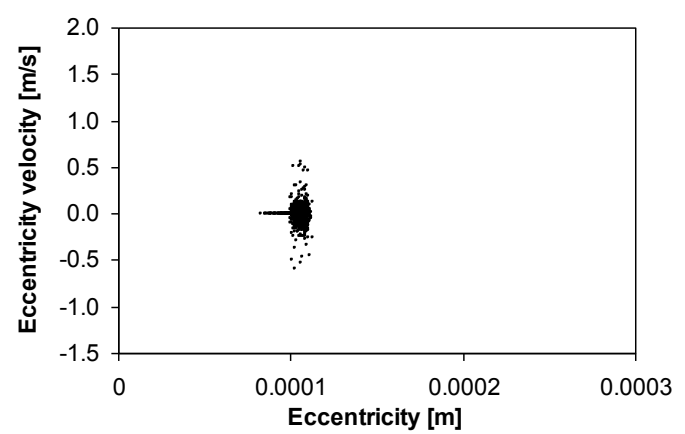

(c)

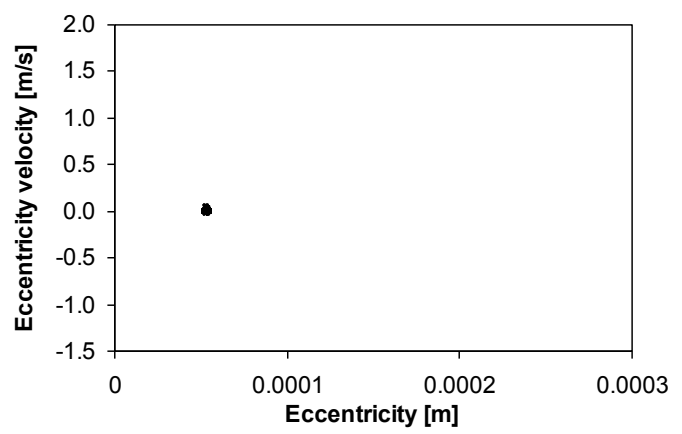

(b)

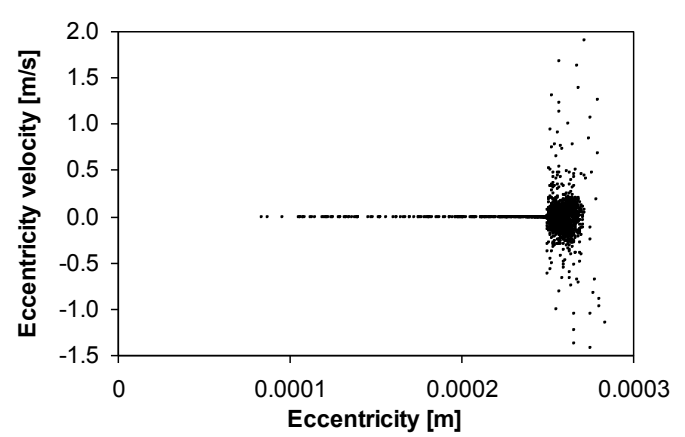

(d)

Figure 9. Poincaré maps for different diametric clearance sizes: (a) $c=0.05 \mathrm{~mm}$; (b) $\mathrm{c}=0.10 \mathrm{~mm}$; (c) $\mathrm{c}=0.20 \mathrm{~mm}$; (d) $\mathrm{c}=0.50 \mathrm{~mm}$.

In the Figs. 6 through 9, the slider acceleration, the joint reaction force, the journal center trajectories and the Poincaré maps are used to illustrate the dynamic behavior of the slider-crank mechanism when different diametric clearance sizes are considered. The values for the diametric 
clearance of the revolute joint are chosen to be $0.05,0.10,0.20$ and $0.50 \mathrm{~mm}$. The two last values are clearly exaggerated in order to study the influence of the variation of the clearance size on the system's dynamic response. Figure 6 shows that when the clearance size is increased the dynamic system behavior tends to be non periodic. This idea is supported by the higher peaks in the slider acceleration curves, which means that impacts followed by rebounds take place, instead of continuous or permanent contact between the journal and bearing walls. When the clearance is small, the system response tends to be closer to the ideal response meaning that the journal and bearing experiment a smaller number of impacts and the journal follows the bearing wall. Hence, the clearance joint behavior tends to be periodic instead of nonlinear or chaotic. This observation can be drawn by examination of Fig. 7 relative to the joint reaction force. The level of peaks force increase with the increasing the clearance size, owing to the higher number of impacts that take place. This conclusion can be confirmed in the journal center trajectories plots and in the respective Poincaré maps displayed in Figs. 8 and 9, respectively. Observing Fig. 8 it can be drawn that for larger clearances there are some periods in which journal is in freeflight motion inside the bearing boundaries. In fact, for clearance size equal 0.2 and $0.5 \mathrm{~mm}$ the three types of journal motion are observed, namely, the free-flight motion, the impact mode and the permanent or continuous contact mode. From the Poincaré maps analysis, the slider-crank mechanism behavior can easily be characterized, and it is possible to distinguish between periodic, quasi-periodic and chaotic responses, when the clearance size increases. This chaotic response suggests that impacts followed by some rebounds take place. Figure 9(a) shows a quasiperiodic motion, because the orbits fill up the Poincaré maps in a fully predictable manner, thus, there is no sensitive dependence on the initial conditions. It is clear that when the clearance is reduced the dynamic response tends to be periodic or regular, which indicates that the journal follows the bearing wall. In fact, in mechanical systems nonlinearities arise from intermittent motion, clearance joints, friction effect, and contact forces, among others. The relation between the clearance size and the type of motion observed is clearly identified from plots in Figs. 8 and 9.

\subsection{Influence of the input crank speed: one clearance joint}

The influence of the input crank speed on the dynamic behavior of the slider-crank mechanism is investigated in this section. Again, in the simulation of the mechanism, only one joint is modeled as clearance joint, that is, the joint that connects the connecting rod and slider. 


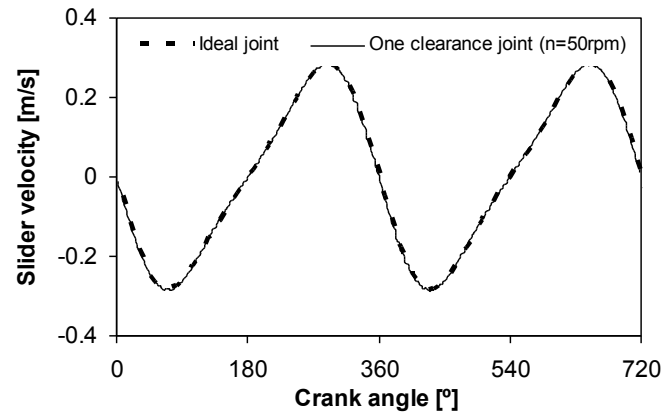

(a)

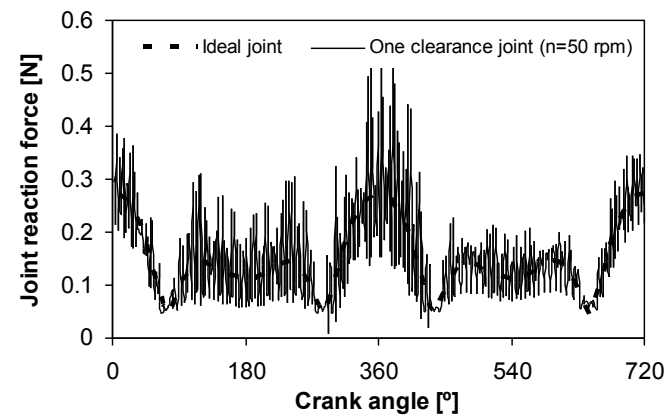

(c)

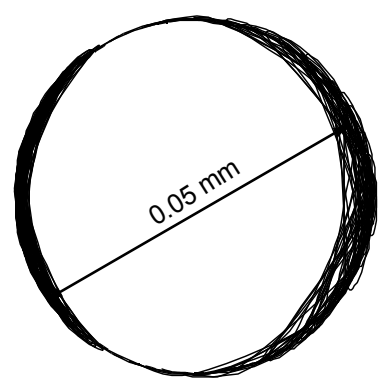

(e)

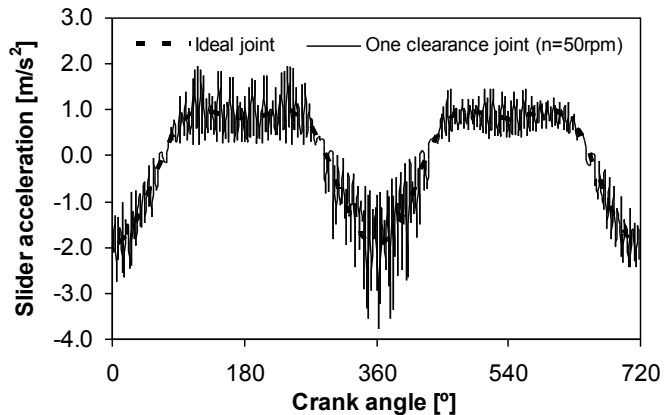

(b)

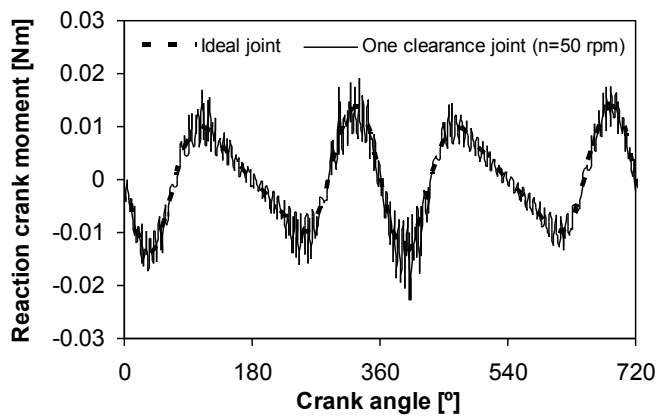

(d)

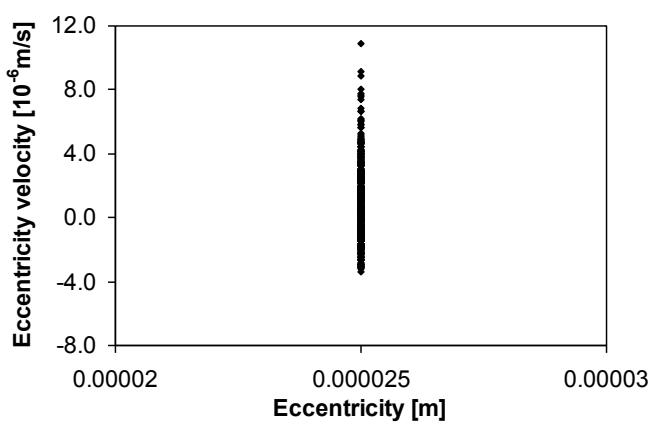

(f)

Figure 10. (a) Slider velocity; (b) Slider acceleration; (c) Joint reaction force at the clearance joint; (d) Crank moment required to maintain its angular velocity constant; (e) Journal center trajectory relative to the bearing center; (f) Poincaré map.

Figure 10 illustrates the global results for the simulation in which the diametric clearance size is equal to $0.05 \mathrm{~mm}$ and the input crank speed is of $50 \mathrm{rpm}$. The effect of the clearance joint is evident on the system's response, namely, in high peaks on the slider acceleration, joint reaction force and crank moment. These peaks are associated with the contact-impact forces developed in clearance joint. Since in this simulation the input crank speed is relatively low (50 rpm) the journal is almost always in permanent contact with bearing wall, as illustrated in Fig. 10(e). Hence, the system's behavior tends to be quasi-periodic as it is visible in the respective Poincaré map of Fig. 10(f), where a strange attractor is evident and is also a strong indicator for this quasi-periodic response.

The influence of the input crank speed on the dynamic response of the slider-crank mechanism is illustrated in Figs. 11 to 14. Four different values for input crank speed were 
selected, chiefly, 50, 500, 1000 and $5000 \mathrm{rpm}$. These different input crank speeds imply the use of different scales for results plotted. By and large, the influence of the clearance joint on the output results is similar for all crank speed simulations, that is, the slider acceleration and joint reaction force curves present peaks due to collisions between the journal and bearing. From Fig. 13 it can be observed that the relative deformation between the journal and bearing increases with the crank speed, because the impacts are severer. In addition, for higher values for crank speed, the system's behavior tends to be nonlinear, as it is quite visible in Poincaré maps of Fig. 14.

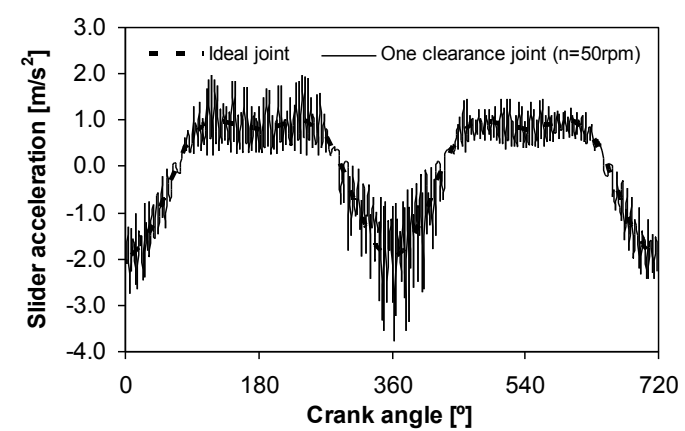

(a)

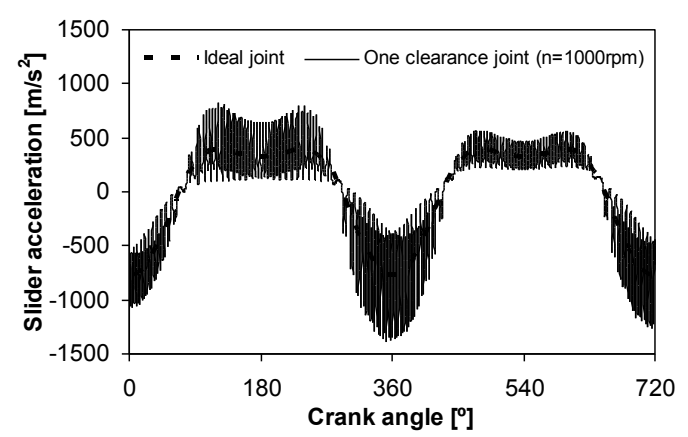

(c)

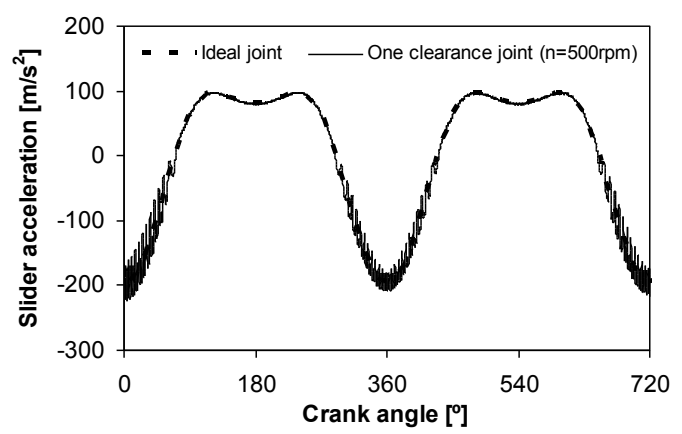

(b)

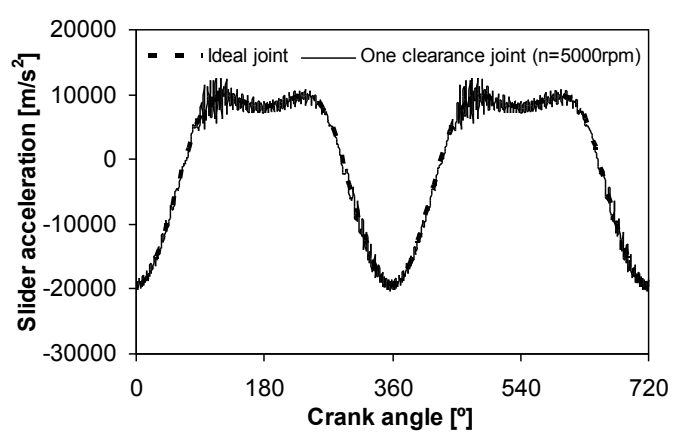

(d)

Figure 11. Slider acceleration for different crank speed values: (a) $n=50 \mathrm{rpm}$; (b) n=500 rpm; (c) $\mathrm{n}=1000 \mathrm{rpm} ;$ (d) $\mathrm{n}=5000 \mathrm{rpm}$. 


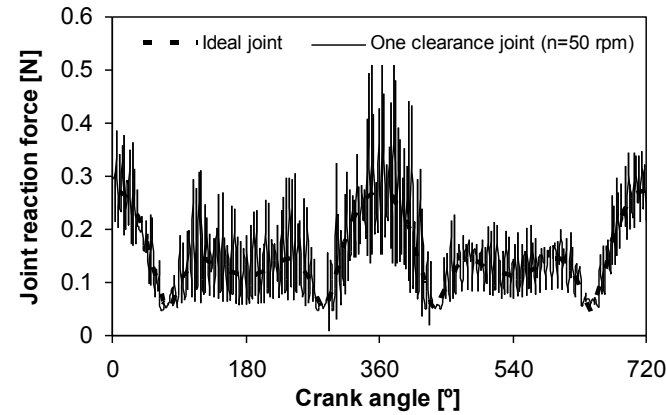

(a)

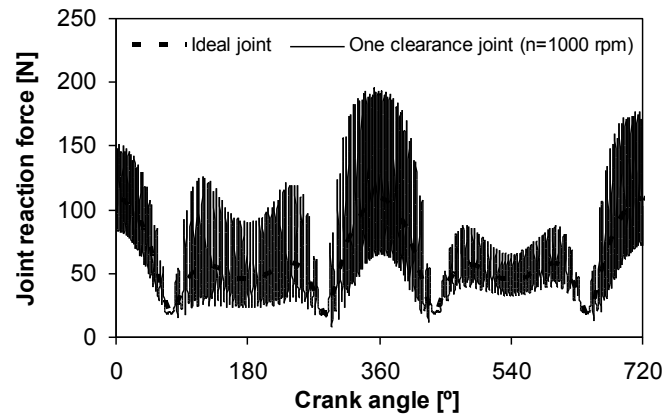

(c)

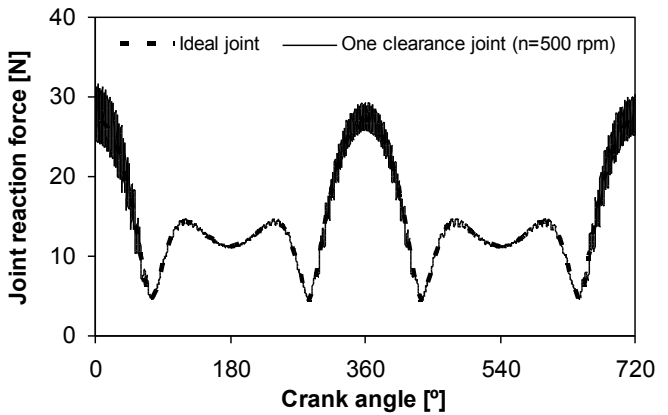

(b)

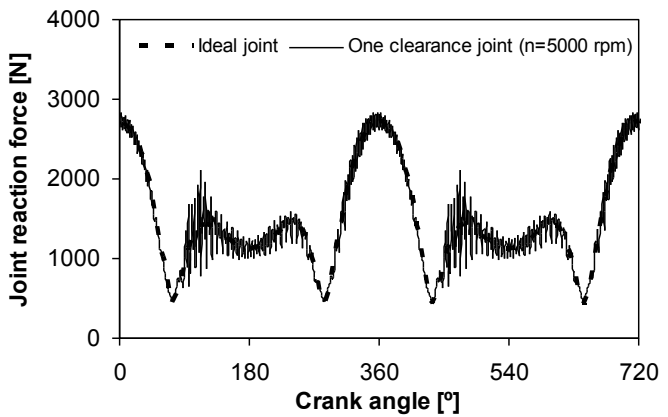

(d)

Figure 12. Joint reaction force for different crank speed values: (a) $n=50 \mathrm{rpm}$; (b) $n=500 \mathrm{rpm}$; (c) $\mathrm{n}=1000 \mathrm{rpm}$; (d) $\mathrm{n}=5000 \mathrm{rpm}$.

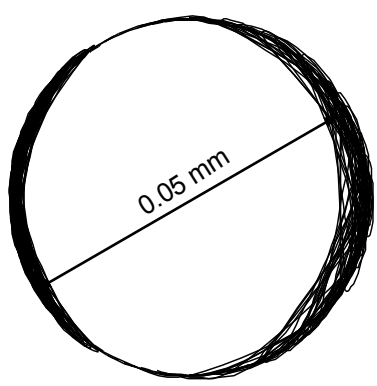

(a)

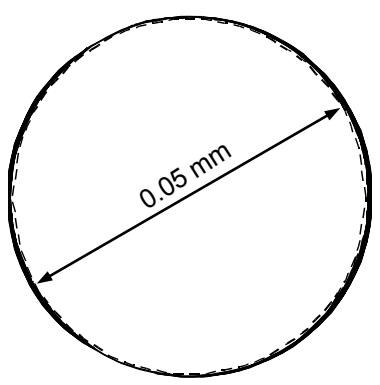

(c)

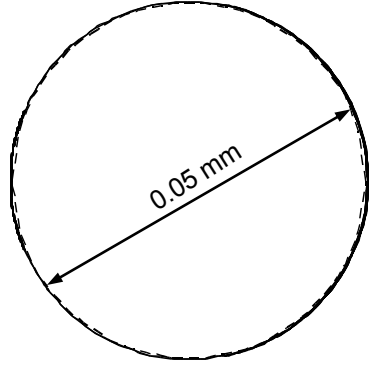

(b)

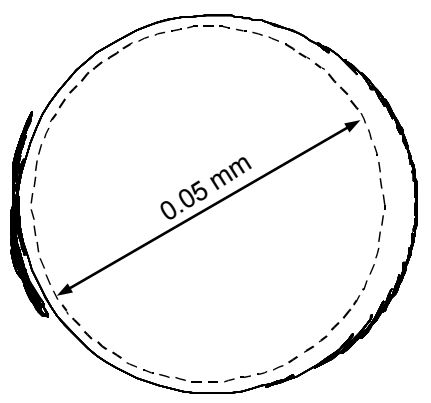

(d)

Figure 13. Journal center trajectories for different crank speed values: (a) $n=50 \mathrm{rpm}$; (b) $n=500$ rpm; (c) n=1000 rpm; (d) n=5000 rpm. 


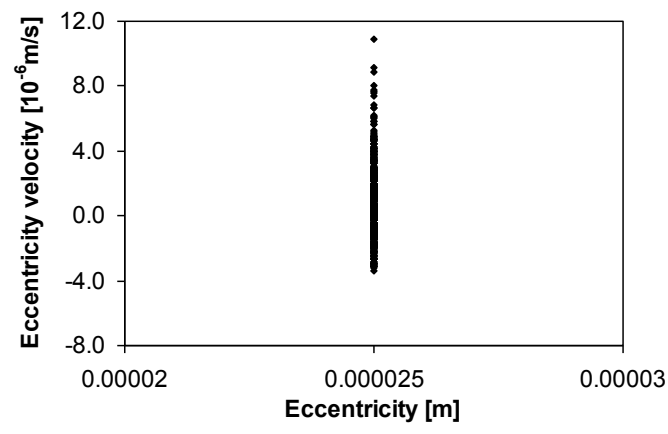

(a)

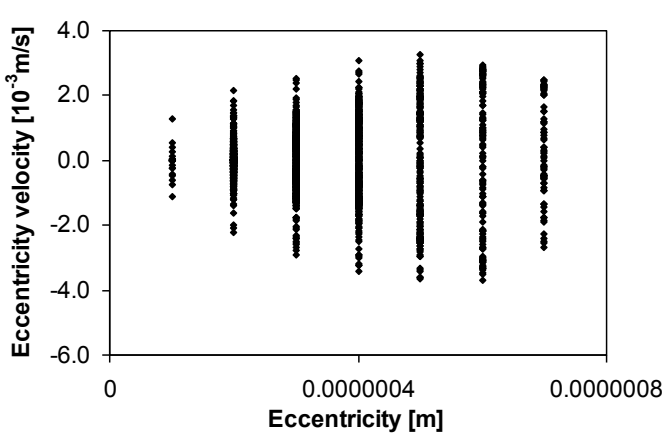

(c)

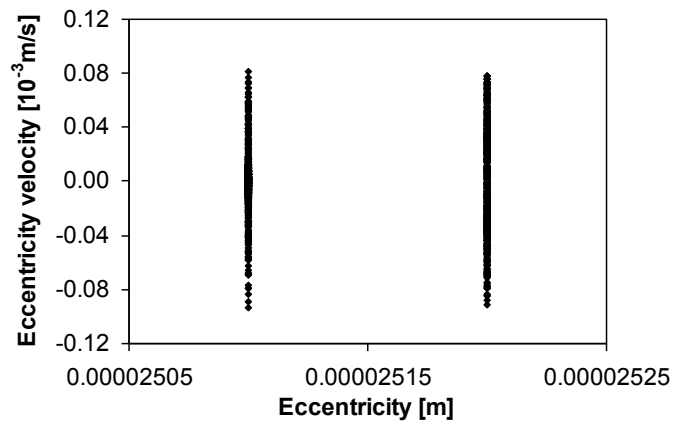

(b)

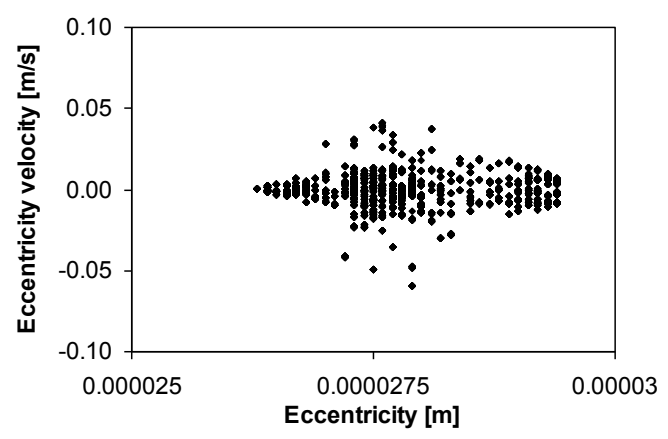

(d)

Figure 14. Poincaré maps for different crank speed values: (a) n=50 rpm; (b) n=500 rpm; (c) $\mathrm{n}=1000 \mathrm{rpm}$; (d) $\mathrm{n}=5000 \mathrm{rpm}$.

\subsection{Influence of the number of clearance joints: one, two and three clearance joints}

The influence of the number of clearance joints on the dynamic response of the slidercrank mechanism is analyzed in this section. The simulation of the mechanism is performed with one, two and three clearance joints.

Figure 15 shows the global results for the case in which the joint that connects the crank and connecting rod is modeled as clearance joint with $0.05 \mathrm{~mm}$ for diametric clearance size, being the system operating at $5000 \mathrm{rpm}$. In general, the results, as expected, are dependent on the contact-impact phenomena that take place between the journal and bearing. From Fig. 15(e) it can be observed that the journal and bearing are in permanent or continuous contact mode. The system's response is also chaotic, as illustrated in Fig. 15(f).

Figures 16 to 19 illustrate the results obtained when the mechanism is modeled with one, two and three clearance joints, being the global system's response similar, namely in what concerns with peaks on the slider acceleration and joint reaction force. It have to be noted that the journal trajectories and Poincaré maps have similar look for all the cases simulated, as illustrated in Figs. 18 and 19. 


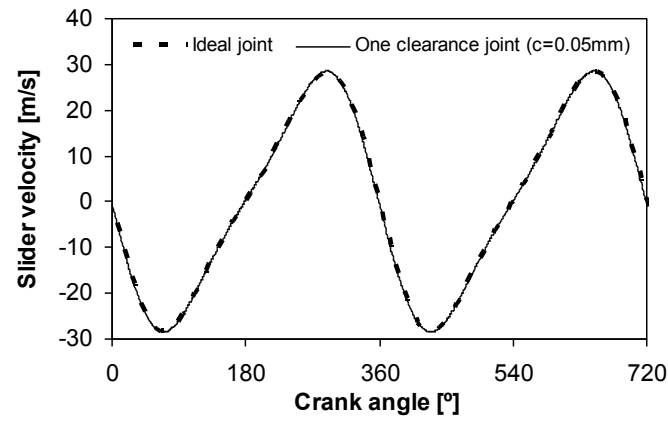

(a)

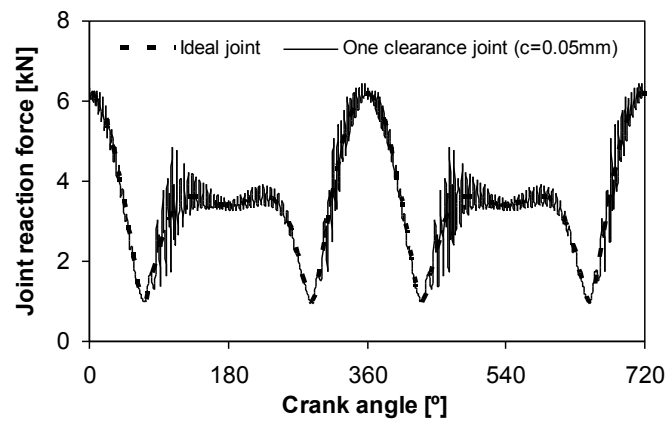

(c)

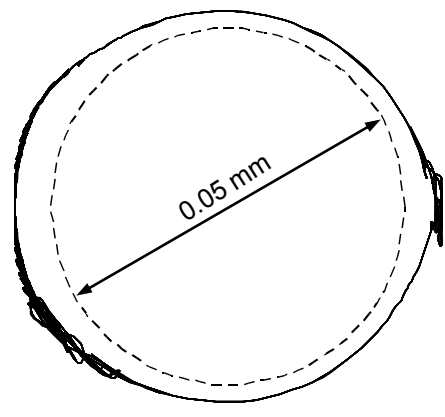

(e)

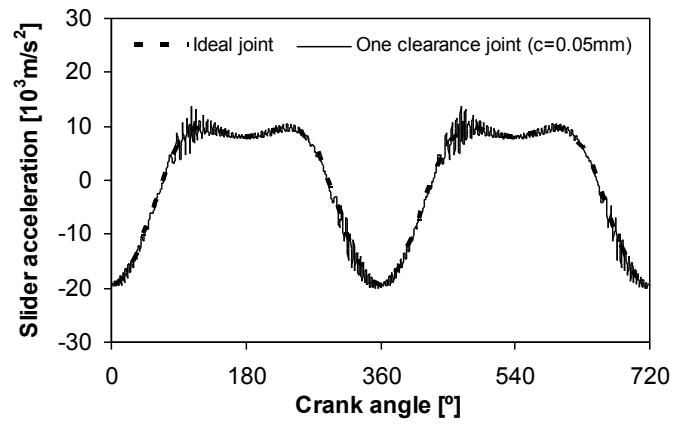

(b)

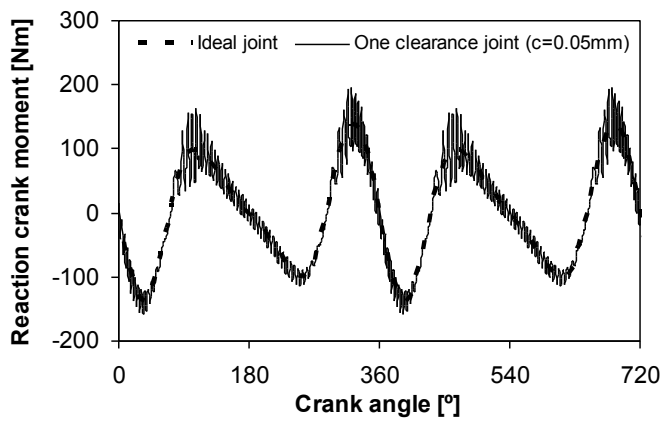

(d)

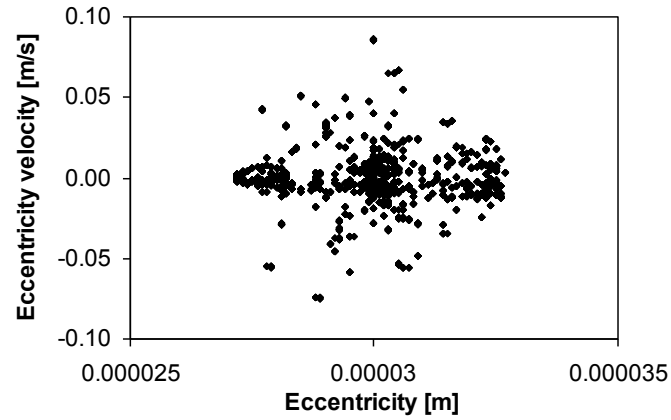

(f)

Figure 15. (a) Slider velocity; (b) Slider acceleration; (c) Joint reaction force at the clearance joint; (d) Crank moment required to maintain its angular velocity constant; (e) Journal center trajectory relative to the bearing center; (f) Poincaré map. 


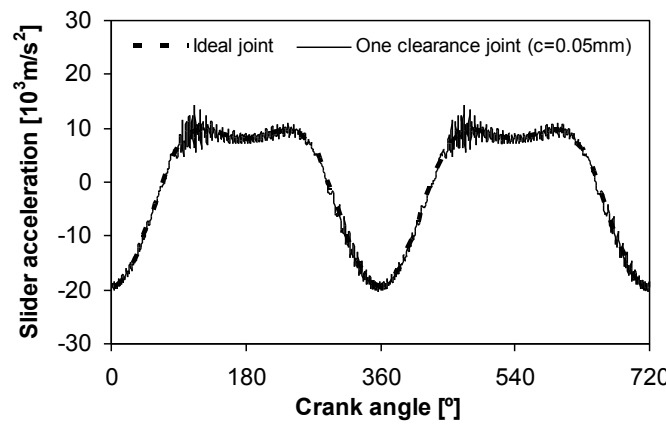

(a)

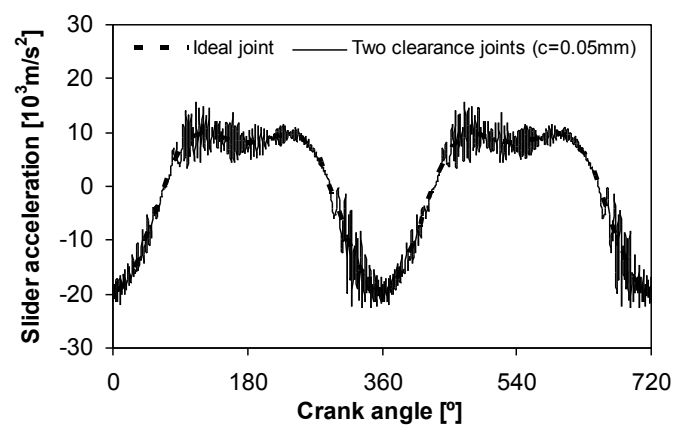

(c)

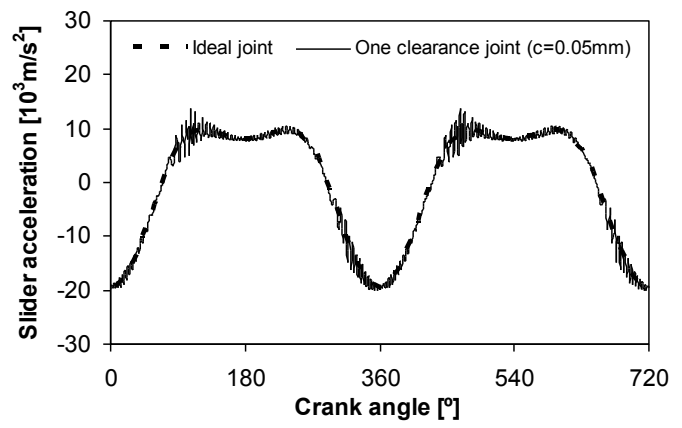

(b)

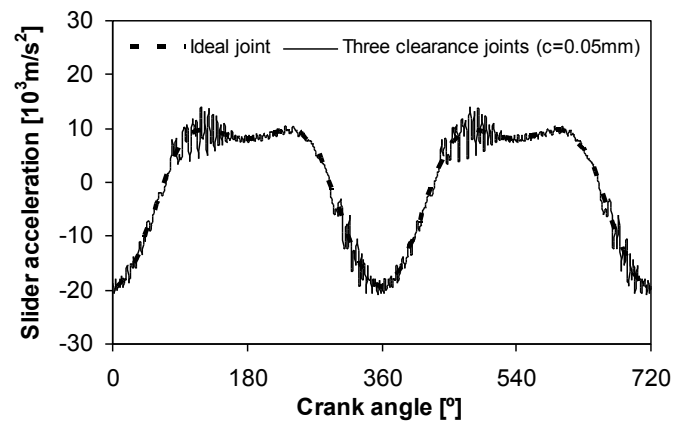

(d)

Figure 16. Slider acceleration for different number of clearance joints: (a) One clearance joint between connecting rod and slider; (b) One clearance joint between crank and connecting rod;

(c) One clearance joint between crank and connecting rod and one clearance joint between connecting rod and slider; (d) All three revolute joints have clearance.

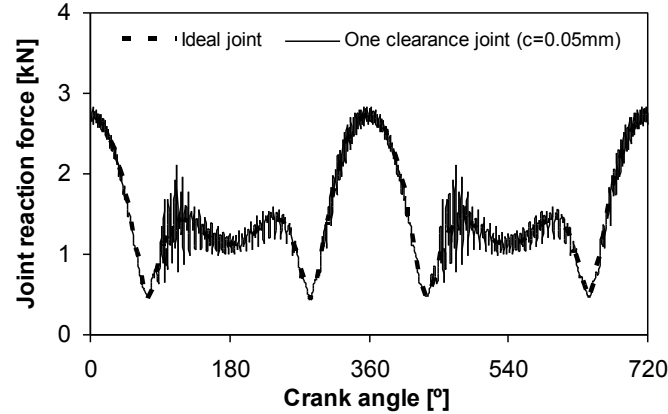

(a)

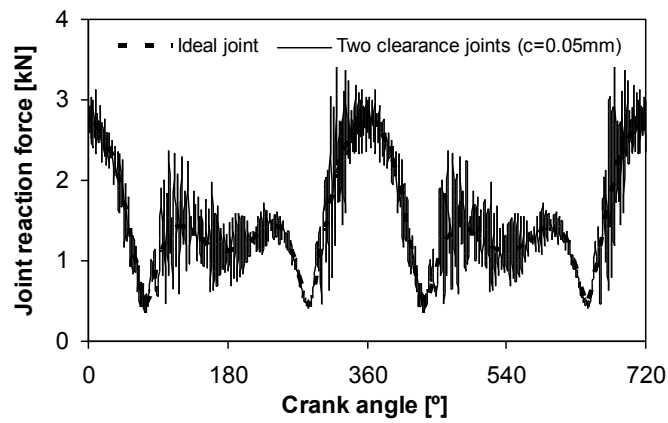

(c)

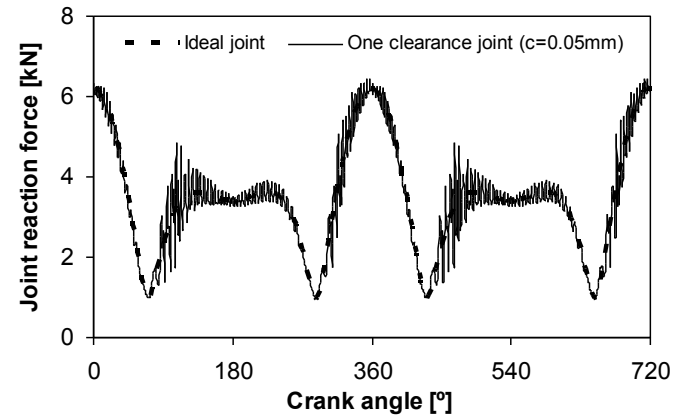

(b)

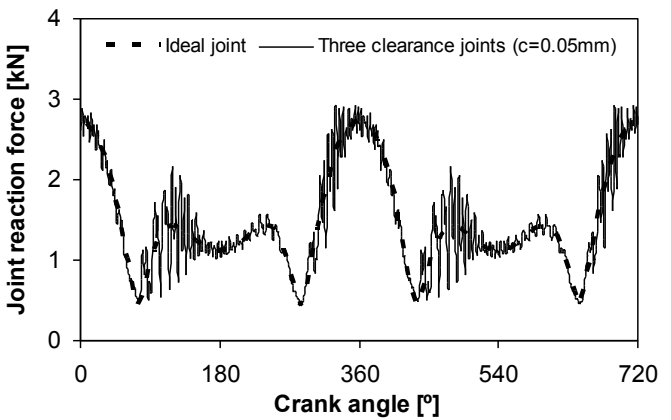

(d)

Figure 17. Joint reaction force for different number of clearance joints: (a) One clearance joint between connecting rod and slider; (b) One clearance joint between crank and connecting rod;

(c) One clearance joint between crank and connecting rod and one clearance joint between connecting rod and slider; (d) All three revolute joints have clearance. 


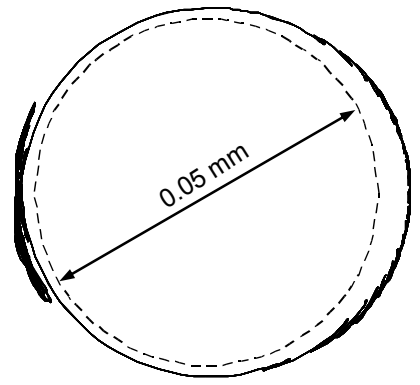

(a)

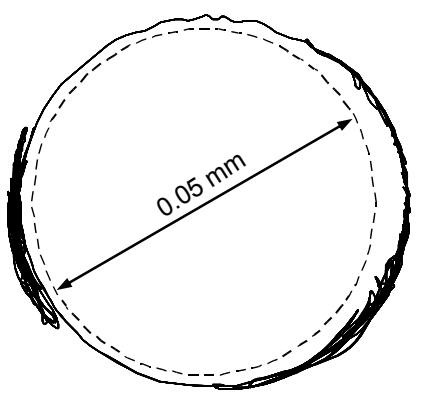

(c)

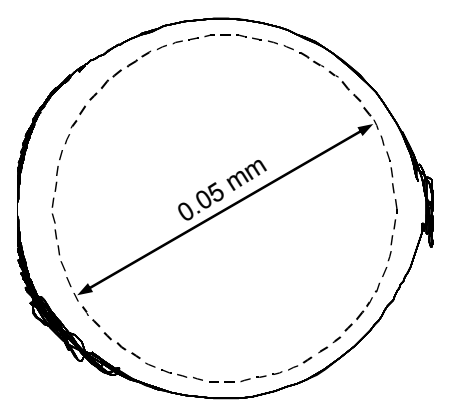

(b)

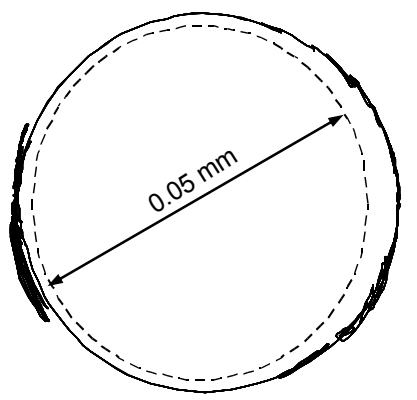

(d)

Figure 18. Journal center trajectories for different number of clearance joints: (a) One clearance joint between connecting rod and slider; (b) One clearance joint between crank and connecting rod; (c) One clearance joint between crank and connecting rod and one clearance joint between connecting rod and slider; (d) All three revolute joints have clearance.

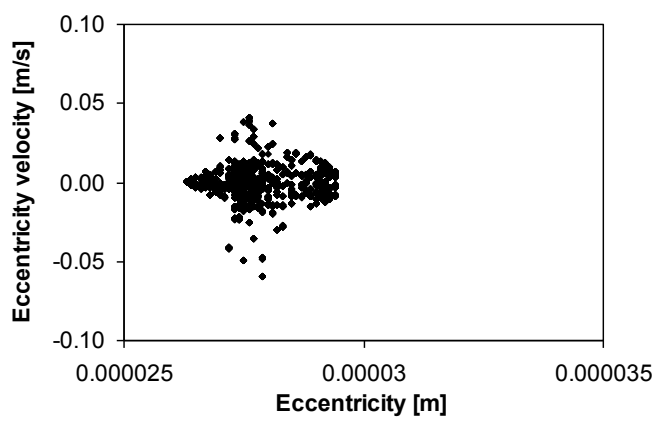

(a)

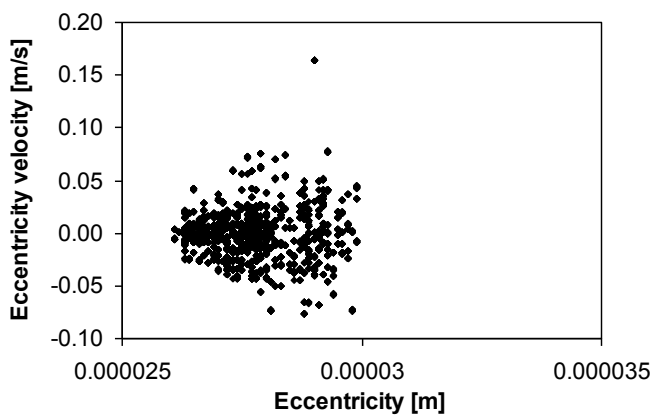

(c)

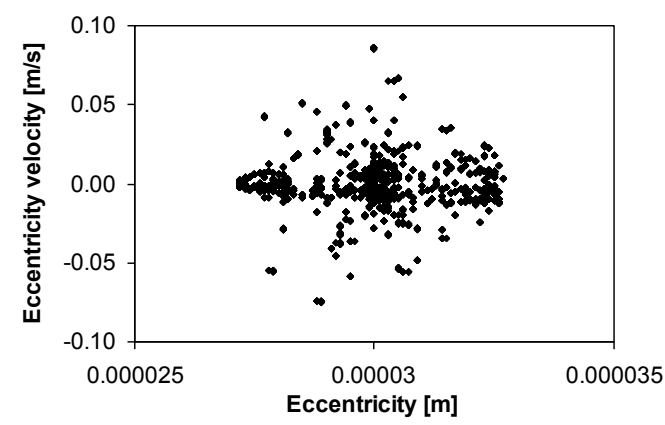

(b)

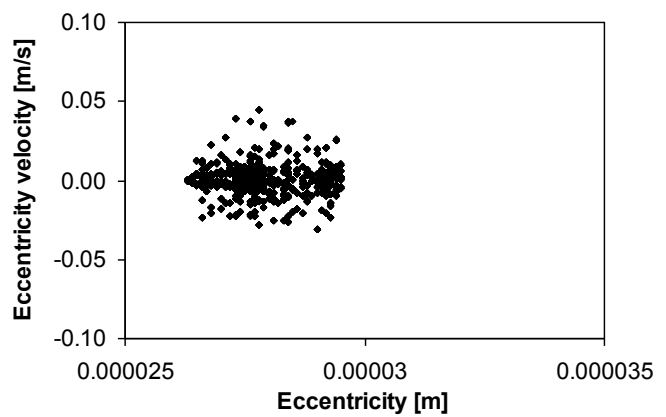

(d)

Figure 19. Poincaré maps for different number of clearance joints: (a) One clearance joint between connecting rod and slider; (b) One clearance joint between crank and connecting rod;

(c) One clearance joint between crank and connecting rod and one clearance joint between connecting rod and slider; (d) All three revolute joints have clearance.

Finally, it is important to analyze the computation time consumed in each simulation performed in the previous section. Figure 20 shows the computation time wasted for the three 
parameters studied, namely, the diametric clearance size, the input crank speed and the number of joint modeled as clearance joints. By observing Fig. 20, the first conclusion is that the computation time decreases when the number of clearance joints included in the system increase. Secondly, the computation time increases with clearance size and decreases when the number of joints modeled as clearance joints increases too. The variation of the input crank speed does not influence significantly the total amount of computation time. The computational simulations were performed in a Pentium $4(3.2 \mathrm{GHz})$ computer. For this purpose, a FORTRAN code named MUBODYNA (acronym for Multibody Dynamics). This program has been developed by author for dynamic analysis of general planar multibody systems [70].

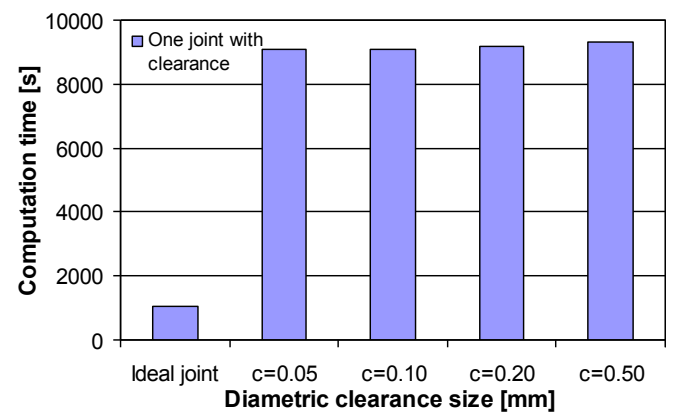

(a)

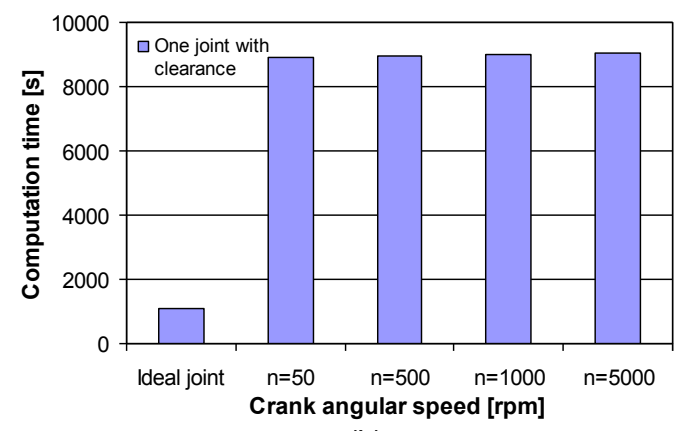

(b)

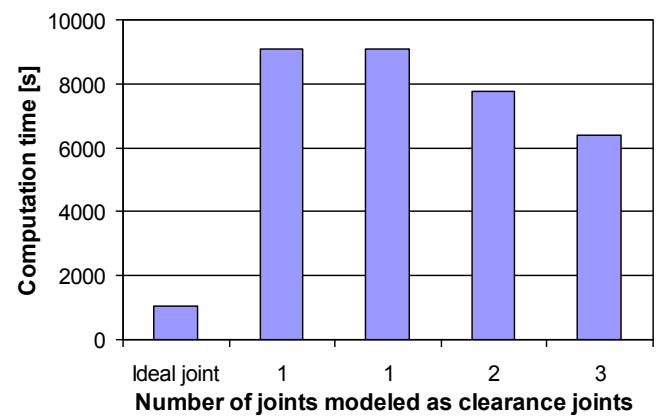

(c)

Figure 20. Variation of the computation time consumed: (a) Diametric clearance size; (b) Input crank angular speed; (c) Number of joints with clearance.

\section{Concluding Remarks}

A general methodology for modeling and simulating multiple clearance joints in rigid multibody systems was presented and discussed throughout this work. The equations of motion that govern the dynamic response of the general multibody systems incorporate the contact forces due to the collisions of the bodies that constitute the clearance joints. A continuous contact force model provides the intra-joint contact-impact forces that develop during the normal operations of the mechanisms. A suitable model for revolute clearance joints is embedded into the multibody systems methodology. An elementary slider-crank mechanism was used to demonstrate the methodology proposed and to perform a parametric study. The main functional parameters were used for this study, namely, the diametric clearance size, the input crank speed 
and the number of joints modeled as clearance joints. In addition, the computation time was evaluated in each simulation in order to test the numerical efficiency. In general, the presented methodology is simple, general and cheap from computational view point. This particular issue has not been addressed before in the literature.

From the numerical simulations performed, it can be concluded that there are considerable changes in joint reaction forces and on the crank moments due to the effect of clearances. These changes are mainly due to the peaks observed in the slider acceleration curves. It is also important to note that the magnifications of forces and moments in the slider-crank mechanism as affected by revolute clearance joints essentially depend on the clearance size and input crank speed. From the main results obtained in this work, it can be also observed that multibody systems with clearance joints are well known as nonlinear dynamic systems that, under certain conditions, exhibit a chaotic response. From the results presented above, it is found that the dynamics of the revolute clearance joint in mechanical systems is sensitive to the clearance size value operating conditions. With a small change in one of these parameters the response of the system can shift from chaotic to periodic and vice-versa.

Finally, it should be highlighted that the results presented in this paper represent an upper bound of the joint reaction forces and crank moments due to the existence of clearance joints, since the elasticity of bodies and lubrication action in the joints were not included in the analysis. These effects tend to reduce the values of these joint reaction forces and crank moments. Moreover, lubrication could also change the entire behavior of the mechanism.

\section{Acknowledgements}

This work is supported by the Portuguese Foundation for the Science and Technology under the research project BIOJOINTS (PTDC/EME-PME/099764/2008). The author would also like to acknowledge the anonymous reviewers for their insightful comments and suggestions on an earlier draft of this paper.

\section{References}

[1] Nikravesh, P.E.: Computer-Aided Analysis of Mechanical Systems. Prentice-Hall, Englewood Cliffs, New Jersey, (1988)

[2] Haug, E.J.: Computer-Aided Kinematics and Dynamics of Mechanical Systems - Volume I: Basic Methods. Allyn and Bacon, Boston, Massachusetts, (1989)

[3] Shabana, A.A.: Dynamics of Multibody Systems, John Wiley and Sons, New York, (1989)

[4] Nikravesh, P.E.: Planar Multibody Dynamics: Formulation, Programming, and Applications. CCR Press, London, (2008)

[5] McCarthy, J.M.: Geometric Design of Linkages: Systems and Controls. Springer, New York, (2000)

[6] Flores, P., Ambrósio, J., Claro, J.C.P., Lankarani, H.M.: Kinematics and Dynamics of Multibody Systems with Imperfect Joints: Models and Case Studies. In Lecture Notes in Applied and Computational Mechanics Vol. 34, Berlin Heidelberg New-York, Springer-Verlag, (2008) 
[7] Flores, P., Ambrósio, J., Claro, J.C.P., Lankarani, H.M.: Dynamics of Multibody Systems with Spherical Clearance Joints. Journal of Computational and Nonlinear Dynamics, 1(3), 240-247, (2006)

[8] Flores, P., Ambrósio, J., Claro, J.C.P.: Lankarani, H.M., Koshy, C.S. Lubricated revolute joints in rigid multibody systems. Nonlinear Dynamics, 56(3), 277-295, (2009)

[9] Ambrósio, J., Veríssimo, P., Sensitivity of a vehicle ride to the suspension bushing characteristics. Journal of Mechanical Science and Technology, 23, 1075-1082, (2009)

[10] Park, J., Nikravesh, P.E.: Effect of Steering-Housing Rubber Bushings on The Handling of a Vehicle. SAE Paper 970103, SAE, Warrendale, Pennsylvania, (1997)

[11] Flores, P., Ambrósio, J., Claro, J.C.P., Lankarani, H.M., Koshy, C.S.: A study on dynamics of mechanical systems including joints with clearance and lubrication. Mechanism and Machine Theory, 41(3), 247-261, (2006)

[12] Lankarani, H.M., Nikravesh, P.E.: A Contact Force Model With Hysteresis Damping for Impact Analysis of Multibody Systems. Journal of Mechanical Design, 112, 369-376 (1990)

[13] Flores, P., Ambrósio, J., Claro, J.C.P. Lankarani, H.M.: Influence of the contact-impact force model on the dynamic response of multibody systems. Proceedings of the Institution of Mechanical Engineers, Part-K Journal of Multi-body Dynamics, 220, 21-34, (2006)

[14] Ambrósio, J., Verissimo, P.: Improved bushing models for general multibody systems and vehicle dynamics. Multibody System Dynamics, 22, 341-365 (2009)

[15] Flores, P., Lankarani, H.M.: Spatial rigid-multi-body systems with lubricated spherical clearance joints: modeling and simulation. Nonlinear Dynamics, DOI 10.1007/s11071-009-9583-z (2009)

[16] Dubowsky, S., Freudenstein, F.: Dynamic Analysis of Mechanical Systems With Clearances, Part 1: Formulation of Dynamic Model. Journal of Engineering for Industry, 93(1), 305-309, (1971)

[17] Dubowsky, S., Freudenstein, F.: Dynamic Analysis of Mechanical Systems With Clearances, Part 2: Dynamic Response. Journal of Engineering for Industry, Series B, 93(1), 310-316, (1971)

[18] Dubowsky, S., Gardner, T.N.: Design and Analysis of Multilink Flexible Mechanism With Multiple Clearance Connections. Journal of Engineering for Industry, 99(1), 88-96, (1977)

[19] Kakizaki, T., Deck, J.F., Dubowsky, S.: Modeling the Spatial Dynamics of Robotic Manipulators with Flexible Links and Joint Clearances. Journal of Mechanical Design, 115, 839-847, (1993)

[20] Bengisu, M.T., Hidayetoglu, T., Akay, A.: A Theoretical and Experimental Investigation of Contact Loss in the Clearances of a Four-Bar Mechanism. Journal of Mechanisms, Transmissions, and Automation Design, 108, 237-244, (1986)

[21] Bauchau, O.A., Rodriguez, J.: Modelling of Joints with Clearance in Flexible Multibody Systems. International Journal of Solids and Structures, 39, 41-63, (2002)

[22] Innocenti, C.: Kinematic Clearance Sensitivity Analysis of Spatial Structures With Revolute Joints. Journal of Mechanical Design, 124, 52-57, (2002)

[23] Wu, W., Rao, S.S.: Interval Approach for the Modeling of Tolerances and Clearances in Mechanism Analysis. Journal of Mechanical Design, 126, 581-592, (2004)

[24] Farahanchi, F., Shaw, S.:Chaotic and Periodic Dynamics of a Slider-Crank Mechanism with Slider Clearance. Journal of Sound and Vibration, 177(3), 307-324, (1994)

[25] Rhee, J., Akay, A.: Dynamic Response of a Revolute Joint with Clearance. Mechanism and Machine Theory, 31(1), 121-124, (1996)

[26] Flores, P., Ambrósio, J., Claro, J.C.P., Lankarani, H.M.: Dynamic behaviour of planar rigid multibody systems including revolute joints with clearance. Proceedings of the Institution of Mechanical Engineers, Part-K Journal of Multi-body Dynamics, 221(2), 161-174, (2007)

[27] Ryan, R.R.: ADAMS-Multibody System Analysis Software, Multibody Systems Handbook, Berlin, Springer-Verlag., (1990)

[28] Smith, R.C., Haug, E.J.: DADS-Dynamic Analysis and Design System, Multibody Systems Handbook, Berlin, Springer-Verlag, (1990) 
[29] Gilardi, G., Sharf, I.: Literature survey of contact dynamics modeling. Mechanism and Machine Theory 37(10), 1213-1239, (2002)

[30] Flores, P., Leine, R., Glocker, R.: Modeling and analysis of rigid multibody systems with translational clearance joints based on the nonsmooth dynamics approach. Multibody System Dynamics, 23(2), 165-190, (2010)

[31] Flores, P., Ambrósio, J., Claro, J.P.: Dynamic Analysis for Planar Multibody Mechanical Systems with Lubricated Joints', Multibody System Dynamics, 12, 47-74, (2004)

[32] Flores, P., Ambrósio, J.: On the contact detection for contact analysis in multibody systems. XXII ICTAM, 22nd International Congress of Theoretical and Applied Mechanics, Adelaide Convention Centre, Adelaide, Australia, August 25-29, 2p, (2008)

[33] Flores, P.: Contact-impact analysis in multibody systems based on the nonsmooth dynamics approach. Post Doctoral Report, ETH-Zurich, Switzerland, (2009)

[34] Pfeifer. F., Glocker C.: Multibody dynamics with unilateral constraints, John Wiley and Sons, New York, (1996)

[35] Anitescu, M., Potra, F.A, Stewart, D.E.: Time-stepping for three-dimensional rigid body dynamics. Computer Methods in Applied Mechanics and Engineering 177(3), 183-197, (1999)

[36] Pang, J-S., Stewart, D.E.: Differential variational inequalities, Math. Program. 113, 345-424, (2008)

[37] Tasora, A., Negrut, D., Anitescu, A.: Large-scale parallel multi-body dynamics with frictional contact on the graphical processing unit. Proceedings of the Institution of Mechanical Engineers, Part-K Journal of Multi-body Dynamics, 222, 315-326, (2008)

[38] Glocker, C., Studer, C.: Formulation and preparation for numerical evaluation of linear complementary systems in dynamics. Multibody System Dynamics, 13, 447-463 (2005)

[39] Förg, M., Pfeiffer, F., Ulbrich, H.: Simulation of Unilateral Constrained Systems with Many Bodies. Multibody System Dynamics, 14(2), 137-154, (2005)

[40] Pfeiffer, F., Foerg, M., Ulbrich, H.: Numerical aspects of non-smooth multibody dynamics. Computer Methods in Applied Mechanic and Engineering 195(50-51), 6891-6908, (2006)

[41] Brogliato, B., Ten Dam, A.A., Paoli, L., Genot, F., Abadie, M.: Numerical simulations of finite dimensional multibody nonsmooth mechanical systems. Applied Mechanics, 55, 107-150, (2002)

[42] Glocker, C., Pfeiffer, F.: Complementarity Problems in Multibody Systems with Planar Friction. Archive of Applied Mechanics, 63(7), 452-463, (1993)

[43] Pang, J., Trinkle, J.C.: Complementarity formulations and existence of solutions of dynamic multirigid-body contact problems with Coulomb friction. Mathematical Programming, 73(2), 199-226 (1996)

[44] Trinkle, J.C., Tzitzouris, J.A., Pang, J.S.: Dynamic multi-rigid-body systems with concurrent distributed contacts. Philosophical Transactions: Mathematical, Physical and Engineering Sciences, 359(1789), 2575-2593, (2001)

[45] Pfeiffer, F.: The idea of complementarity in multibody dynamics. Archive of Applied Mechanics, 72(11-12), 807-816, (2003)

[46] Signorini, A.: Sopra alcune questioni di elastostatica. Atti della Societa Italian per il Progresso della Scienza, (1933)

[47] Moreau, J.J.: Application of convex analysis to some problems of dry friction. Trends in Applications of Pure Mathematics to Mechanics, (H. Zorski, Ed.) London, U.K.: Pitman, 2, 263 $280,(1979)$

[48] Panagiotopoulos, P.D., Inequality Problems in Mechanics and Applications. Convex and Nonconvex Energy Functionals. Birkhäuser-Verlag., Basel, Boston, Stuttgart, (1985)

[49] Kwak, B.M.: Complementarity Problem Formulation of Three-Dimensional Frictional Contact. Journal of Applied Mechanics, 58, 134-140, (1991)

[50] Anitescu, M., Potra, F.A.: Formulating Dynamic Multi-Rigid-Body Contact Problems with Friction as Solvable Linear Complementarity Problems. Nonlinear Dynamics, 14(3), 231-247, (1997) 
[51] Brogliato, B.: Some perspectives on the analysis and control of complementarity systems. IEEE Transactions on Automatic Control, 48(6), 918-935 (2003)

[52] Leine, R.I., Nijmeijer, H.: Dynamics and Bifurcations of Non-Smooth Mechanical Systems. Lecture Notes in Applied and Computational Mechanics Vol. 18, Berlin Heidelberg New-York, Springer-Verlag, (2004)

[53] Timoshenko, S.P., Goodier, J.N.: Theory of Elasticity, McGraw Hill, New York, (1970)

[54] Hertz, H.: On the contact of solids - On the contact of rigid elastic solids and on hardness, (Translated by D. E. Jones and G. A. Schott), Miscellaneous Papers, MacMillan and Co. Ltd., London, 146-183, (1896)

[55] Mansour, W.M., Townsend, M.A.: Impact Spectra and Intensities for High-speed Mechanisms. Journal of Engineering for Industry, 97(2), 347-353, (1975)

[56] Miedema, B., Mansour W.M.: Mechanical Joints with Clearance: a Three Mode Model. Journal of Engineering for Industry, 98(4), pp. 1319-1323, (1976)

[57] Haines, R.S.: Survey: 2-Dimensional Motion and Impact at Revolute Joints. Mechanism and Machine Theory, 15, 361-370, (1980)

[58] Flores, P.: Dynamic Analysis of Mechanical Systems with Imperfect Kinematic Joints. Ph.D. Dissertation, Mechanical Engineering Department, University of Minho, Guimarães, Portugal, (2005)

[59] Srivastava, N., Haque, I.: Clearance and friction-induced dynamics of chain CVT drives. Multibody System Dynamics, 19(3), 255-280, (2008)

[60] Erkaya S., Uzmay I.: A neural-genetic (NN-GA) approach for optimising mechanisms having joints with clearance. Multibody System Dynamics, 20(1), 69-83, (2008)

[61] Erkaya S., Uzmay I.: Investigation on effect of joint clearance on dynamics of four-bar mechanism. Nonlinear Dynamics, 58(1-2), 179-198, (2009)

[62] Zukas, J.A., Nicholas, T., Greszczuk, L.B., Curran, D. R.: Impact Dynamics, John Wiley and Sons, New York, (1982)

[63] Goldsmith, W.: Impact - The Theory and Physical Behaviour of Colliding Solids, Edward Arnold Ltd, London, (1960)

[64] Greenwood, D.T.: Principles of Dynamics. Prentice Hall, Englewood Cliffs, New Jersey, (1965)

[65] Nikravesh, P.E.: Initial condition correction in multibody dynamics. Multibody System Dynamics, 18, 107-115, (2007)

[66] Baumgarte, J.: Stabilization of Constraints and Integrals of Motion in Dynamical Systems. Computer Methods in Applied Mechanics and Engineering, 1, 1-16, (1972)

[67] Gear, W.W.: Numerical Initial Value Problems in Ordinary Differential Equations. Prentice-Hall, Englewood Cliffs, New Jersey, (1971)

[68] ANSY, Y14.5M-1994, Dimensional and Tolerancing. ASME, New York, (1994)

[69] Wiggins, S.: Introduction to Applied Nonlinear Dynamical Systems and Chaos. Springer Verlag, New York, (1990)

[70] Flores, P.: MUBODYNA - A FORTRAN program for dynamic analysis of planar multibody systems. University of Minho, Guimarães, Portugal, (2010) 